\title{
NASA Langley Experimental Aerothermodynamic Contributions to Slender and Winged Hypersonic Vehicles
}

\author{
Scott A. Berry and Karen T. Berger \\ NASA Langley Research Center, Hampton VA 23681
}

Additional Experimental Support Provided by:

Gregory J. Brauckmann, Gregory M. Buck, Brian R. Hollis, Thomas J. Horvath, Derek S. Liechty, Michelle L. Mason, Kelly J. Murphy, Matthew N. Rhode, Shann J. Rufer, and William A. Wood

A review of recent NASA Langley Research Center experimental aerothermodynamic contributions to slender and winged hypersonic flight programs is presented. Significant findings and lessons learned are highlighted and discussed for a range of high profile national flight programs. In many cases, the experimental results are shown to be crucial to the success of these programs. To assure success with future hypersonic flight programs, experimental aerothermodynamic facilities will be required to provide invaluable support both pre-and post-flight.

\section{Introduction}

This paper highlights NASA Langley Research Center's (LaRC) experimental contributions and lessons learned in support of recent national and agency hypersonic flight initiatives, with the focus on slender to moderately blunt lifting body configurations. Hollis, et al. (Ref. 1) provided a similar review of experimental accomplishments and contributions specifically for blunt reentry configurations. These two papers are intended as complements to cover the spectrum of blunt to lifting body configurations. The scope for the present review will be limited to highlighting significant aerothermodynamic impacts derived primarily from experimental studies conducted in LaRC's Aerothermodynamic Laboratory (LAL) over the past 20 years. Aerothermodynamics, by definition a blend of aerodynamics, aeroheating, and fluid dynamics, is crucial for design and development of advanced space transportation and trans-atmospheric vehicles. Other disciplines, such as structures, materials, propulsion, avionics, and guidance, navigation and control, require aerothermodynamic information to complete a design cycle for a hypersonic vehicle. Current sources for aerothermodynamic input include ground-based facilities (i.e. wind tunnels), computational fluid dynamics (CFD) and/or engineering codes, and flight experiments. Not long ago (for instance during the early design phase for the Space Shuttle Orbiters), the wind tunnel was the primary source of data used to derive the flight environments and vehicle aero and thermal responses. Today, CFD is more often in the critical path of the vehicle design process, with wind tunnels providing support. Despite the trend, a case can be made that hypersonic experimental facilities will continue to be critical to national interests with space access and military applications.

A synergistic combination of ground-based testing, CFD predictions, and targeted flight experiments is the best approach, currently, for defining aerothermodynamic environments for highspeed and access-to-space vehicles. These three components provide balance with cross checks and validation during the design process. Wind tunnels provide rapid assessment and screening of vehicle configurations early in the design cycle. Later, wind tunnels can also provide CFD validation data for benchmark of final design environments. CFD, once validated, provides a comprehensive assessment of both laminar and turbulent flight environments at select points along a trajectory. Since the scope of the CFD component is largely dictated by the accuracy required for any given mission, expense can be reduced by validation against experimental data. One reason not to try an all-CFD design approach is the question of how to deal with the issue of boundary layer transition. As noted by Heppenhiemer (Ref. 2): "Experience has shown that CFD falls short in two areas: prediction of transition to turbulence, which sharply increases drag due to skin friction, and in the simulation of turbulence itself." Along with the increase in drag, turbulence also leads to a sharp increase in frictional heating. Thermal protections system (TPS) design is predicated on having an accurate assessment of the heating profile at all points along the design flight trajectory, thus being able to predict when transition would occur is paramount. Ideally, there is time and budget to allow for 
targeted flight experiments to verify functionality of the final design prior to a program being deemed operational. By utilizing all three approaches for aerothermodynamic design, each individual component can be reinforced and strengthened through final comparisons of the extracted flight performance data to wind tunnel simulations and CFD predictions. The advantage that modern CFD brings to the table is the potential for significant reduction in the amount of ground-based testing that is required to close the design loop. As discussed by Haney, ${ }^{3}$ the Shuttle aeroheating design cycle depended exclusively on wind tunnel data from 50 test entries in seven national facilities over a period of 12 years. During that span, nine configuration changes were tested requiring a total of 5200 hours of test time. Even a small reduction in the time and costs associated with a similar effort can result in significant savings.

U.S. hypersonic funding has been notoriously cyclical over the years. Periodic slumps and surges of federal support have had long-term ramifications with reduced capabilities, both in terms of infrastructure and corporate knowledge (personnel), as discussed by Miller. ${ }^{4}$ For instance, after the strong build-up of capabilities for the Apollo and Shuttle programs, a deep decline occurred in the mid 1980's, when less than 2 people worked experimental aeroheating full-time at LaRC. This was soon followed by significant growth and support largely starting with National Aerospace Plane (NASP) advocacy. The NASP upswing highlights a significant issue with this cyclical funding behavior as it took several years of facility upgrades to return neglected tunnels and infrastructure back to world-class status (and to hire and train the new crop of engineers and scientists needed to be proficient in the use of those facilities). Thus, there is a significant phase lag between the funding increase that is triggered by a national need and the resulting surge in capability that is ready to support said need. Over most of the past 20+ years, funding and support for hypersonics has been relatively stable. Recently, the NASA investment portfolio for Aeronautics has shifted away from hypersonics to emphasize low-speed commercial airframe manufacturers.

With diminishing funds for hypersonics, experimental capabilities are presently at risk. Facility funding deficits are worsened with the decision to no longer support wind tunnels directly, instead requiring projects to "pay-to-use", a paradigm not mirrored in Agency accounting models with use of supercomputing capabilities. Most projects are unlikely to have deep-enough pockets to absorb facility-related overhead, such as the costs associated with operations and upgrades, further contributing to a downward trend. Further, projects by their nature tend to have a near term focus and are not able/willing to fund strategically. Thus with the present funding environment, experimental aerothermodynamic capabilities are regressing to the point of losing facilities. As an example, more than half the seven facilities associated with Shuttle aeroheating database (above) are no longer operational. While CFD continues to mature and improve, the reality is there is at least one technology area that cannot be addressed yet via computational means, specifically boundary/shear layer transition. For the foreseeable future, experimental facilities will be required to study, understand, and even predict boundary layer transition (BLT) at flight conditions. A strong reason for maintaining an experimental capability is to reduce TPS design conservatism, by accounting for BLT onset effects on the integrated heat load and therefore TPS thickness and weight. This paper will highlight examples of invaluable LAL aerothermodynamic support of Shuttle, Hyper-X, various Xplanes, some Department of Defense (DoD) programs, and other more recent efforts.

While the primary focus of the present paper is to review recent LaRC contributions to national hypersonic initiatives and flight programs, an ulterior motive is to provide advocacy for continued investments in hypersonic ground testing capabilities. Sustaining investments in infrastructure are critical to maintain state-of-the-art facilities, test techniques, and know-how, to synergistically complement CFD, to provide physical data for complex phenomenon, and to avoid phase lag when the need is critical. A cautionary note made by former Air Force Chief Scientist and AIAA President, Dr. Mark Lewis, in a three part interview on hypersonic flight test programs and progress in 2011*: "I see across the board an unwillingness to make the investment in testing infrastructure, in some cases, a lack of commitment to continue the investments in infrastructure that we've already paid for. And it's not only the facilities; it's also the people who run the facilities." Further, he states that one

\footnotetext{
* http://www.sldinfo.com/professor-lewis-on-the-evolution-of-hypersonics-and-its-impact-on-the-future-ofwarfare-part-two/
} 
can either "make the investment up front in a test facility, or frankly, ... pay for it in a failed flight, but one way or another, you're going to pay for testing. It's just a matter of when you pay for the testing."

\section{Experimental Facilities \& Capabilities}

The LAL includes four conventional, perfect-gas hypersonic blow-down wind tunnels that can provide Mach 6 and 10 flows over a wide range of unit Reynolds numbers and normal shock density ratios. Three of these facilities are presently operational: the 31-Inch Mach 10 Air Tunnel, the 20Inch Mach 6 Air Tunnel, and the 15-Inch High-Temperature Mach 6 Air Tunnel. The first two of these are considered workhorse facilities as both have been heavily utilized for a majority of the historical testing conducted at the LAL. The 15-Inch Mach 6 tunnel is primarily used for instrumentation development and diagnostics, although it has been used to investigate wall temperature effects when needed. The fourth facility, the 20-Inch Mach $6 \mathrm{CF}_{4}$ Tunnel, is presently mothballed due to budget constraints. As will be illustrated in the subsequent discussion, this heavy gas facility provided some valuable insights into real gas effects, as the thermodynamic properties of $\mathrm{CF}_{4}$ produce shock-density ratios comparable to that of high-temperature, reacting air at Mach numbers $\left(M_{\infty}\right)$ between 13 and 18. With recent CFD modeling improvements that have been shown to fairly accurately model high temperature flow chemistry effects, any arguments for the criticality of keeping an operational $\mathrm{CF}_{4}$ tunnel became difficult once expensive heater/reclaimer repairs were needed. Figure 1 provides an illustration of the applicability of these main facilities to simulating hypersonic conditions across a typical reentry trajectory. Hollis, et al. ${ }^{1}$ also recently reviewed and discussed these facilities, while Micol $^{5,6}$ and Miller ${ }^{4}$ provide an assessment of capabilities and improvements over the years. An updated facilities paper is also being published at the present conference, see Berger, et al. ${ }^{7}$

Both Refs. 1 and 7 provide up-to-date details of the various types of models, instrumentation, and test techniques available for testing within the LAL, thus only a high-level review will be covered here. Interested readers are invited to examine those papers (and most of the other references included herein) for a more detailed discussion of supporting capabilities for testing in the LAL. Aerothermodynamic studies within the LAL can include any combination of aerodynamic, aeroheating, and fluid dynamic testing as required by circumstance. Typically, aerodynamic studies are conducted with force and moment (F\&M) measurements obtained with precision-machined metal models mounted on internal six-component strain-gage balances. Similarly, most aeroheating studies are conducted using the LaRC-developed global phosphor thermography technique ${ }^{8}$ with cast-ceramic models. ${ }^{9}$ Fluid dynamic studies, such as schlieren and oil-flow, can be obtained on either aerodynamic or aeroheating models, and in some cases include off-body measurements such as planar laserinduced fluorescence (PLIF). ${ }^{10}$ All of these techniques will be highlighted in the following discussion.

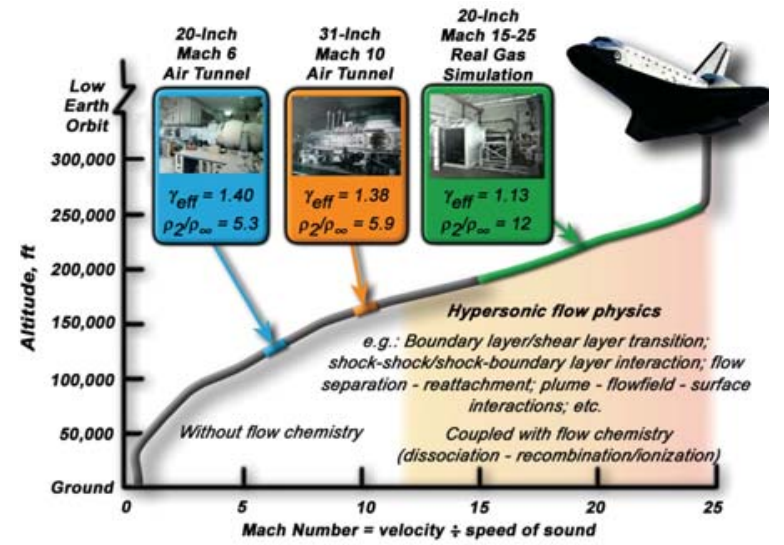

Figure 1. Aerothermodynamic flight simulation within the LAL

\section{Past Flight Program Support and Lessons Learned}

\section{A. Space Shuttle Orbiter}

1. Body Flap Anomaly (1994-1995)

During the first reentry of the Space Shuttle Orbiter (see Fig. 2), a nose-up pitching moment increment $\left(\Delta C_{m}\right)$ was observed during the high Mach number, high altitude segment of the trajectory. This nose-up tendency required twice the body flap (BF) deflection expected for trimmed flight (nearing the operational limit). Sometimes referred to as "the pitch-up anomaly", it was investigated experimentally in the LAL to examine the effects of Mach number, Reynolds number, and ratio of 
specific heats. Complementary computational solutions were obtained for both wind tunnel and flight conditions. Brauckmann, et al. ${ }^{11}$ showed that the primary cause of the anomaly was real gas effects that lowered the pressure on the aft windward surface when compared against those obtained from ideal gas facilities. The lower pressures were a result of lowering the flowfield ratio of specific heats $(\gamma)$ due to high-temperature effects. This effect was accurately simulated in the $\mathrm{CF}_{4}$ tunnel, which utilized a heavy gas and thus provided a lower post-shock value of $\gamma$. The program's early and heavy reliance on ideal gas facilities to generate the

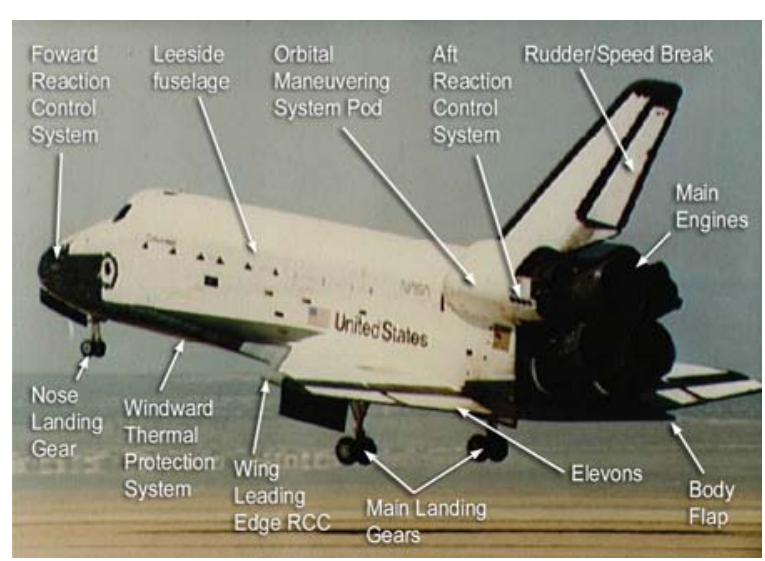

Figure 2. Key Orbiter features shown on photo of STS-1 landing. aerodynamic database (ADB) led to an erroneous expectation that the body flap provided plenty of trim margin during the high Mach number portion of reentry.

Figure 3 (from Ref. 11) provides experimental oil flow visualization of the streamline patterns in the vicinity of the body flap obtained in an ideal gas facility, the 20-Inch Mach 6 tunnel. The model is at a nominal angle of attack $(\alpha)$ of 40 -deg and a body flap deflection $\left(\delta_{B F}\right)$ of 16-deg. The range of Reynolds numbers $(R e)$ provide an indication of the body flap separation region under laminar, transitional, and turbulent conditions. At the lowest $R e$, a sizable separation zone is evident, with reattachment towards the end of the body flap. As $R e$ increases, the size of the separation region shrinks and reattachment moves forward on the body flap (towards the hinge line). At the highest $R e$, the separation is completely gone due to a turbulent boundary layer ahead of the body flap region. Figure 4 (from Ref. 11) provides a comparison of calculated surface streamlines on a 20-deg

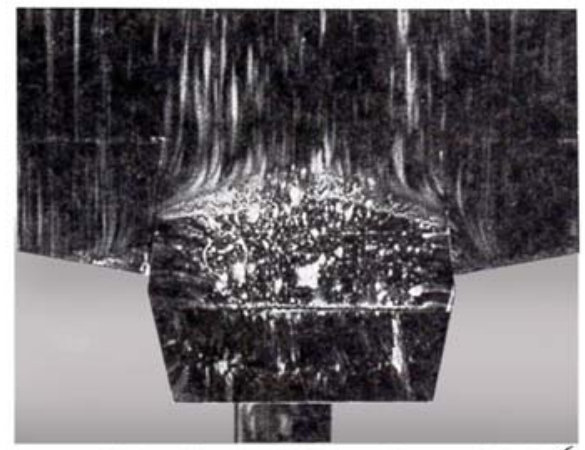

a) $\alpha=40 \mathrm{deg}, \delta_{\mathrm{BF}}=16.0 \mathrm{deg}, \mathrm{Re}_{\mathrm{L}}=0.4 \times 10^{6}$

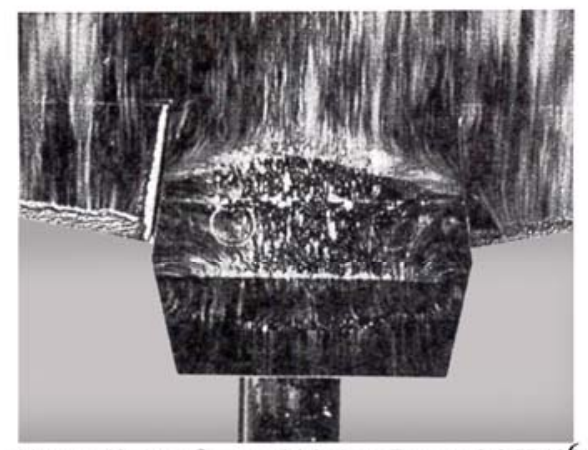

b) $\alpha=40 \mathrm{deg}, \delta_{\mathrm{BF}}=16.0 \mathrm{deg}, \operatorname{Re}_{\mathrm{L}}=0.8 \times 10^{6}$

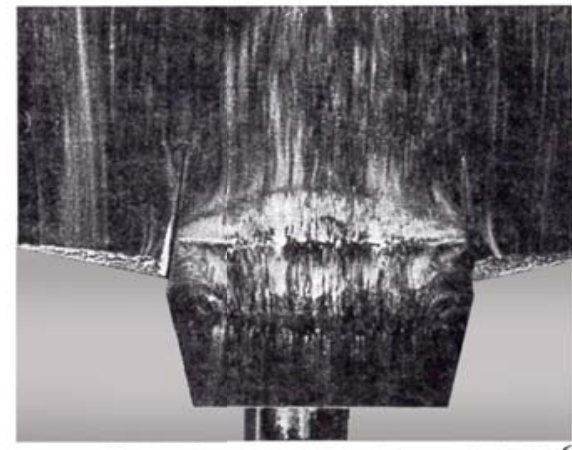

c) $\alpha=40 \mathrm{deg}, \delta_{\mathrm{BF}}=16.0 \mathrm{deg}, \operatorname{Re}_{\mathrm{L}}=1.6 \times 10^{6}$

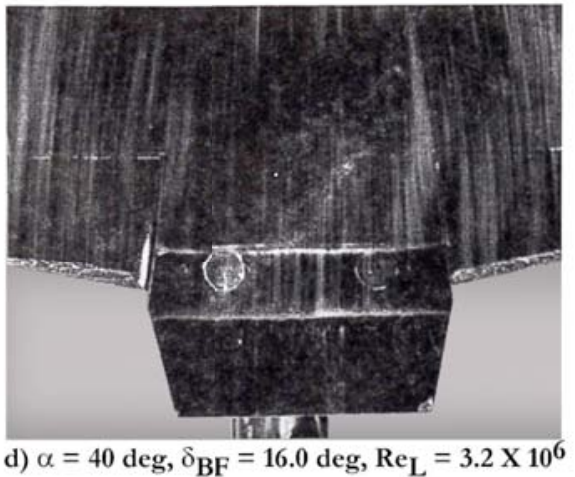

Figure 3. Oil flow visualization of the Shuttle Orbiter body flap region in the 20Inch Mach 6 Air Tunnel (Fig. 3 from Ref. 11). 


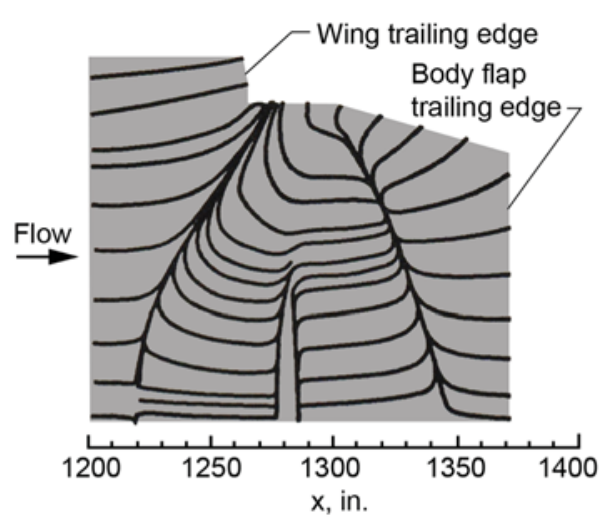

a) Wind Tunnel, $\alpha=\mathbf{4 0}$ deg, $\delta_{\mathrm{BF}}=\mathbf{2 0}$ deg

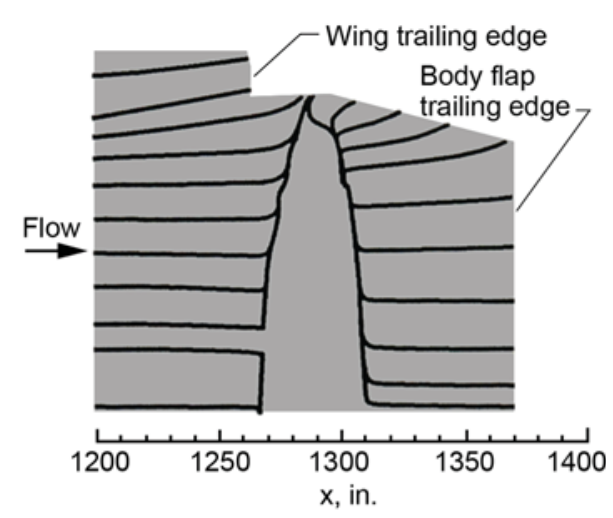

b) Flight, $\alpha=\mathbf{4 0}$ deg, $\delta_{\mathrm{BF}}=\mathbf{2 0} \mathrm{deg}$

Figure 4. Calculated surface streamlines in vicinity of body flap at wind tunnel and flight conditions (Fig. 8 from Ref. 11).

deflected body flap under laminar wind tunnel and flight conditions. The separation zone is smaller for flight with "real gas" conditions. Figure 5 (from Ref. 11) illustrates the aerodynamic impact of testing in a heavy gas facility, such as the $\mathrm{CF}_{4}$ tunnel. The value of $\gamma$ in the $\mathrm{CF}_{4}$ tunnel, around 1.15 in the shock layer, is closer to that determined to occur in flight. A comparison of aerodynamic coefficients obtained in air and at identical Mach and Reynolds numbers reveals a significant pitching moment coefficient $\left(C_{m}\right)$ shift due to testing in a heavy gas. The experimental heavy gas results matches well with the Shuttle flight data.

Although not available at the time of ADB development, post-flight Navier-Stokes computations that included non-equilibrium chemistry were shown to also replicate the pitch-up behavior. These results have also been sited in two NATO AGARD reports. ${ }^{12,13}$ This flight anomaly is an example of the improvements in test capability and CFD modeling that has occurred since the time of the development of the Shuttle pre-flight ADB in the 1970's.

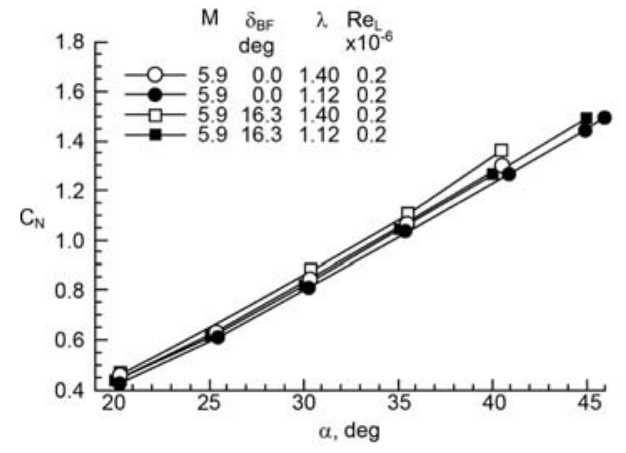

a) Normal force coefficient

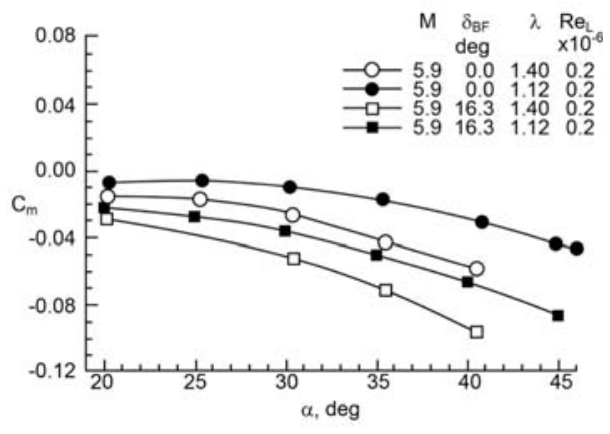

b) Pitching moment coefficient

Figure 5. Comparison of Shuttle Orbiter aerodynamics in air and $\mathrm{CF}_{4}$ (Fig. 9 from Ref. 11).

\section{Asymmetric Boundary Layer Transition (1995-1996)}

After the Space Shuttle Orbiters were deemed fully operational, an issue with the effect of asymmetric BLT was observed in flight. This issue surfaced after several reentries in which reaction control system (RCS) thruster reserves were nearly exhausted to counter unanticipated and unknown yawing moments. These cases happened to be coincident with flights that had noted gap filler protrusions in locations away from the vehicle centerline. It was speculated that the yawing moments resulted from higher drag on only one side of the windward surface due to high-Mach asymmetric BLT. While somewhat obvious now, asymmetric BLT had never been considered before and many in the program had to be convinced that this phenomena was real. The program requested experimental evidence of early BLT from discrete tripping elements and measurement of yawing moments sufficient to require significant RCS usage. The LAL was used to globally image turbulent 
wedges resulting from various locations and trips sizes (see Berry, et al. ${ }^{14}$ ). These results were compared against discretegauge results obtained in AEDC Tunnel B (see Bouslog, et al. ${ }^{15}$ ). Yawing moment increments were also measured, but never published.

Figure 6 (from Ref. 14) provides a sketch of the windward surface locations where tripping elements were to be placed during the test at LAL and at AEDC. These locations were selected to coincide with specific sites of interest based on the flight data. Figure 7 provides a sample global heating map from the 20-Inch Mach 6 Air Tunnel, where a trip was placed just outboard of location $\mathrm{C}$ and the resulting

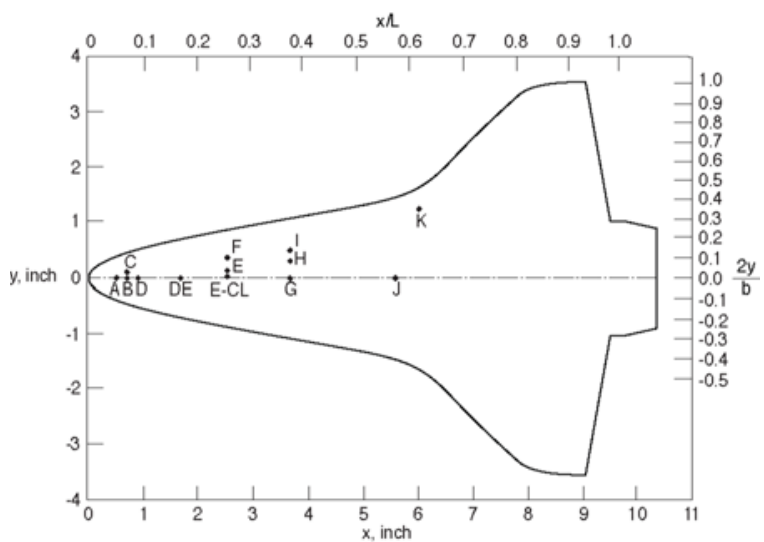

Figure 6. Sketch of Orbiter windward locations for tripping elements (Fig. 1 from Ref. 14).

turbulent wedge almost exactly bisected the windward surface. For this case, the trip height $(k)$ was 0.0075 -in at a unit Reynolds number $(R e)$ of $3.2 \times 10^{6} / \mathrm{ft}$. A scenario like this was thought to responsible for the yawing moment increments observed in flight. One of the most surprising finding from the LAL effort was that a well-behaved roughness transition correlation was identified from the resulting database. Figure 8 provides the correlation, showing 2 curves that define the start and end of transition for any location on the windward centerline based on the momentum thickness Reynolds number over edge Mach number $\left(\operatorname{Re}_{e} / M_{e}\right)$ and trip height to boundary layer thickness $(k / \delta)$. The start of transition, usually referred to as incipient, is identified when the trip is just big enough to force transitional heating somewhere downstream and the end of transition, usually referred to as effective, is when transitional/turbulent heating is as close to the trip as possible (Fig. 7 is an example of effective). The curve coefficients $(C)$ listed for incipient and effective was based on boundary layer calculations from the BLIMP engineering code. These results were later shown to be consistent with data from other programs (namely X-33 and X-38) ${ }^{16}$ as long as a consistent computational method was used and became the basis for development of a transition prediction methodology for the Shuttle Return-to-Flight effort (to be discussed subsequently).

This wind tunnel program was successful on multiple fronts. First, in providing experimental evidence of the possibility of early BLT. Second, in confirming the off-centerline locations seen from post-flight evidence as likely to result in an asymmetric transition pattern and a yawing moment sufficient to require RCS use. And finally in identifying the well-behaved transition correlation approach that later would be shown to be applicable for several moderately blunt lifting-body configurations. This last one was perhaps the more significant finding due to its influence on several

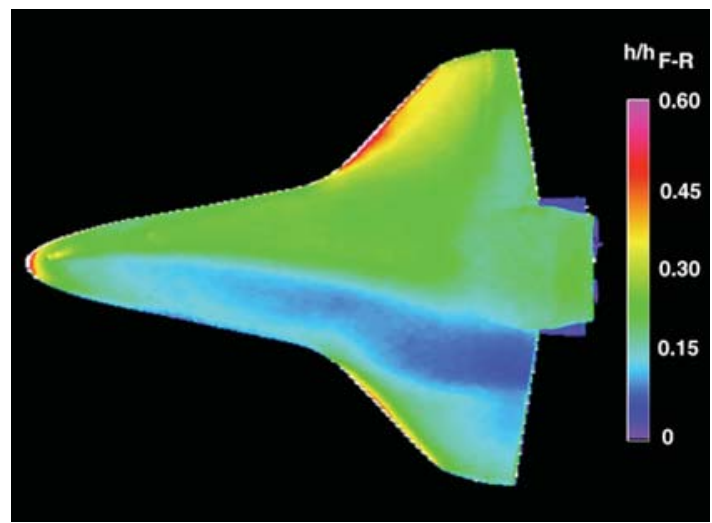

Figure 7. Windward heating image for $k=0.0075$-in trip outboard of location $C$ at $\operatorname{Re}_{\infty}=3.2 \times 10^{6} / \mathrm{ft}$ (Fig. 13 from Ref. 14).

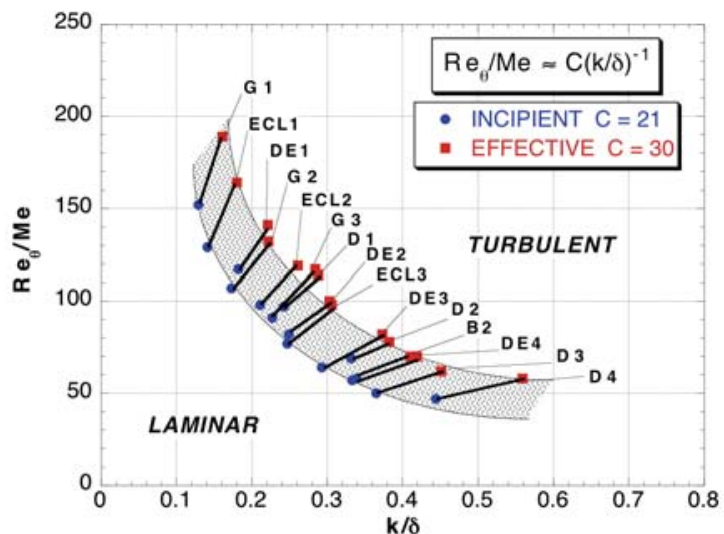

Figure 8. Shuttle Orbiter centerline roughness transition correlation for LaRC 20In Mach 6 Tunnel (Fig. 11 from Ref. 14). 
subsequent experimental efforts.

3. Columbia Accident Investigation (2003-2004)

After the 2003 loss of the Space Shuttle Columbia, the resulting investigation exclusively used the LAL to understand the aerothermodynamic (aerodynamic and convective heating) impact of various TPS damage scenarios. This fast-paced investigation benefitted greatly from the rapid prototyping capability to quickly build and test phosphor coated models (including simultaneous aerodynamic and heating measurements) in step with quickly changing developments. Testing was conducted in the 20-Inch Mach 6 Air and 20-Inch Mach $6 \mathrm{CF}_{4}$ tunnels, the higher shock density ratio in $\mathrm{CF}_{4}$ being critical for accurate simulation of the hypervelocity shock detachment distances. Horvath (Ref. 17) details the ground-based heating

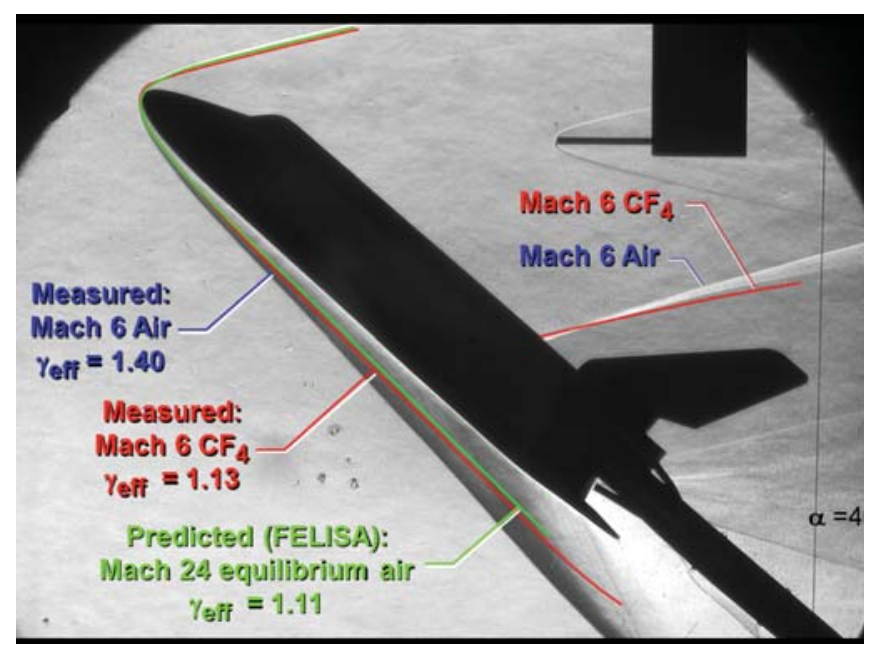

Figure 9. Comparison of shock detachment distances from wind tunnel to flight (Fig. 5 from Ref. 17). results while Brauckmann and Scallion (Ref. 18) provides corresponding aerodynamic results.

Figure 9 provides a comparison of the bow shock locations as seen in the $\mathrm{CF}_{4}$ tunnel to those determined from predicted flight and Mach 6 air. Note that the heavy gas capability allows for closer approximation of the shock behavior at higher Mach number flight conditions. Figure 10 provides an assessment of the leeside flowfield due to one of the investigated Columbia accident scenarios. The combination of oil flow and global heating patterns present a clearer picture of the fluid and thermal impact of various damage scenarios. Figure 11 provides a comparison of Orbiter side fuselage heating patterns due to various wing leading edge damage sites between testing in air and $\mathrm{CF}_{4}$. The use of a heavy gas provided better leeside comparison of the surface heating patterns to flight observations; in this case testing with a missing Reinforced Carbon-Carbon (RCC) wing leading edge panel 9 in $\mathrm{CF}_{4}$ provided local augmentations in very close proximity to the noted thermocouple $(\mathrm{T} / \mathrm{C})$ location. These examples all came from Ref. 17. Finally, Ref. 18 looked at the accident investigation from an aerodynamic perspective, providing F\&M data from cast ceramic models that could be rapidly modified to test various damage scenarios. For instance, Fig. 12 shows the incremental moment coefficients for a progression of damage scenarios in comparison to flight-derived counterparts, providing qualitative agreement and a plausible explanation for the break-up process.

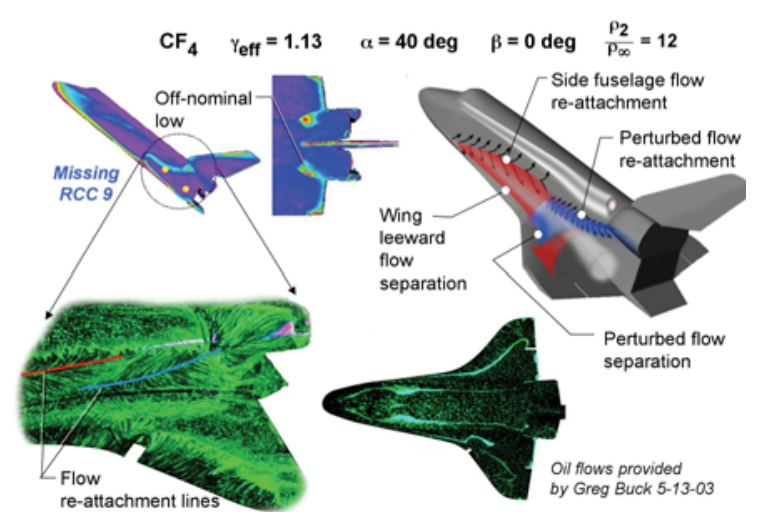

Figure 10. Postulated Orbiter leeside flowfield due to wing leading edge damage (Fig. 29 from Ref. 17).

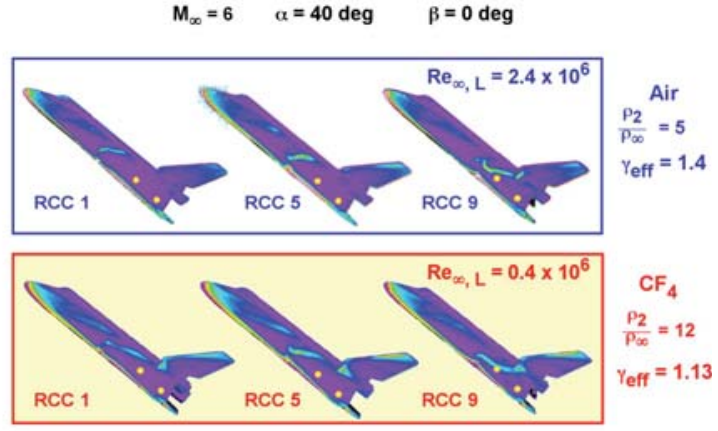

Figure 11. Comparison between Mach 6 air and $\mathrm{CF}_{4}$ of Orbiter side fuselage heating patterns due to wing leading edge damage (Fig. 30 from Ref. 17). 


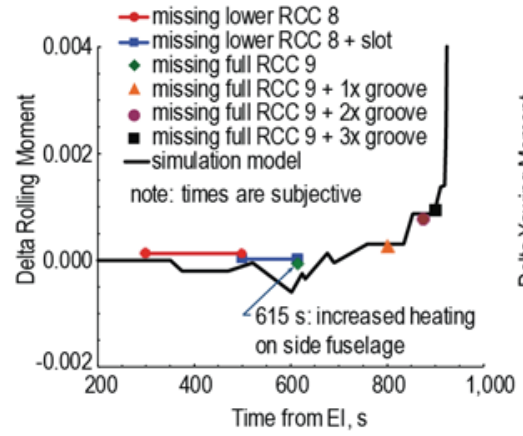

a) Rolling moment

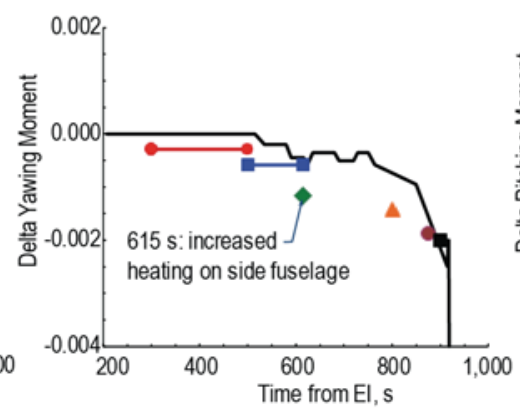

b) Yawing moment

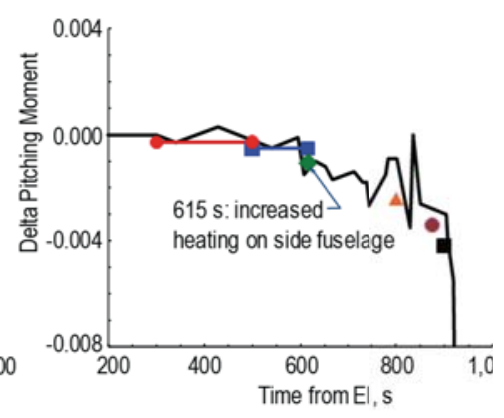

c) Pitching moment

Figure 12. Incremental moment coefficients for progressive damage scenario (Fig. 18 from Ref. 18).

The technical basis for the accident investigation final report was primarily derived from these rapid-fire aerodynamic and heating studies conducted in the LAL, along with corresponding inviscid CFD solutions. The present loss of the $\mathrm{CF}_{4}$ tunnel (and its ability to rapidly simulate and assess high Mach number damage scenarios) hinders potential future investigations. While contemporary CFD capabilities could be used to support and influence just such an investigation, the response time would likely be much longer.

\section{Return to Flight (2005-2010)}

Soon after the accident investigation, the LAL was then mobilized to support the return of the Shuttle program back to flight. While LaRC was directly involved with many aspects of the Return-toFlight (RTF) effort, the LAL was critical to the development of on-orbit damage assessment tools. The specific aeroheating tools generated from LAL data include the cavity heating tool, the BLT tool, and the breaches tool.19 These tools represent a significant experimental effort with multiple entries into LAL facilities. In the case of the BLT Tool, this task was given a head start with the prior development of a workable discrete roughness transition criterion that was shown applicable to midL/D lifting bodies such as the Shuttle, X-33, and X-38, which was a follow on to the earlier discussed asymmetric BLT study. ${ }^{16}$ Using that criterion and approach as a starting point, the RTF BLT Team further refined the criterion through additional testing, engineering-level computational support, and a detailed review of the Shuttle flight transition database for selection of calibration cases. The initial version of the BLT Tool was completed in time for the first RTF mission, STS-114 (see the dedicated AIAA session presented at the San Francisco Conference in 2006). ${ }^{19-23}$

Presented below are two sample results for protuberance and cavity correlations with the BLT Tool Version 2 from Ref. 24. STS-114 immediately demonstrated an inherent weakness of BLT Tool Version 1 with unacceptable uncertainties for high Mach number transition prediction. The team then began work on updates to the tool: conversion to an all-CFD solution boundary layer property database, inclusion of higher Mach number experimental data (including testing at CUBRC LENS at Mach 10 and 16), and revision of the historical flight calibration data. The BLT Tool was instrumental in support of 22 flights after RTF. Collectively, the BLT Tool was based on over 200 occupancy days in 3 LAL facilities, totaling over 1500

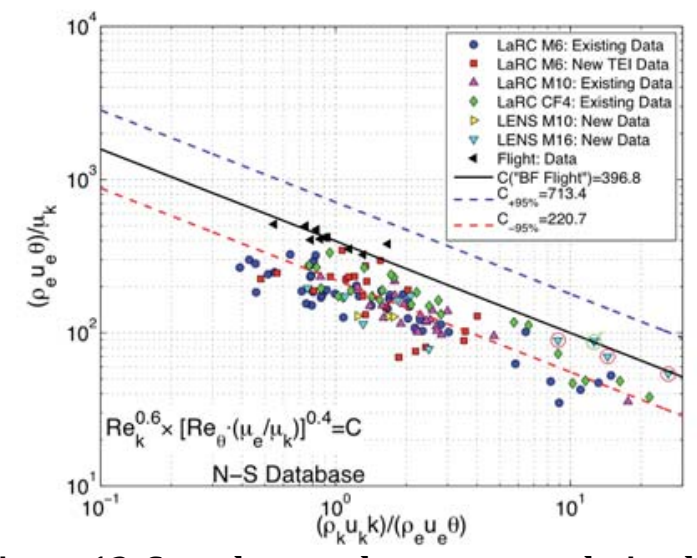

Figure 13. Sample protuberance correlation based on $\mathbf{R e}_{\mathrm{k}}$ approach developed for BLT Tool V2 including comparison to historical flight data (Fig. 11b from Ref. 24). 
runs - a significant investment by the Shuttle flight project.

Cavity heating was another highpriority RTF endeavor within the LAL. Extensive wind tunnel experiments were conducted on a multitude of idealized cavity geometries to establish the aeroheating effects of cavity length, width, depth, sidewall angels, orientation, and surface curvature over a range of fluid dynamic conditions (Mach, Reynolds number, and boundary layer thickness). ${ }^{25,26}$ These results were used to develop engineering screening tools to guide rapid repair decisions during missions. Computational solutions were also assessed against the experimental database for accuracy and range of applicability as a real-time mission back up to the engineering tools. Historically, cavities have been classified as either "open" or "closed" based on the resulting flow pattern. When the boundary layer flow tends to skip over a notionally shorter cavity, it's labeled as open. Conversely, when the flow tends to get ingested into a longer cavity, it's labeled as closed. ${ }^{27}$

Figures 15 and 16, taken from Ref. 27, provide an assessment of laminar predictions for consistent cavity scales over a range of Reynolds numbers. Only laminar predictions were assessed, as peak heating during reentry occurs at laminar flow conditions. At the moderate Reynolds number condition, shown in Fig. 15, the laminar predictions do a reasonable job of capturing and representing the measured heating footprint. This case is likely a closed cavity with the flow being ingested into and recirculating within the long, deep cavity and the computations are qualitatively validated for this case. At the higher Reynolds number, shown in Fig. 16, the laminar prediction suggests a relatively benign heating footprint, with the flow mostly skipping over the cavity. From the computations, one would conclude that the Fig. 16 case is an open cavity even though the dimensional scale is similar to Fig. 15. It should be noted that a thinner boundary layer (due to the higher Reynolds number) requires a shorter, thinner cavity to replicate the dimensional scale. The measurements show a completely different heating footprint with the flow diving deep into the cavity, likely from a transitional or turbulent boundary layer and a large downstream impact. Thus, while laminar predictions can be used as a supplement to the engineering analysis for a subset of likely cavity heating scenarios, clear limitations were identified based on the ground-based experimental effort.

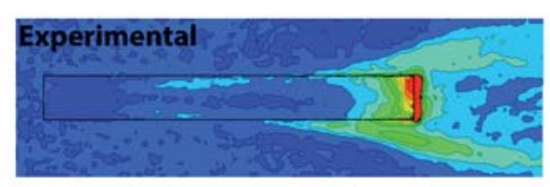

$\mathrm{L} / \mathrm{H}=\mathbf{2 0 . 5}, \mathrm{H} / \delta=2.4, \mathrm{Re}_{\theta}=300$
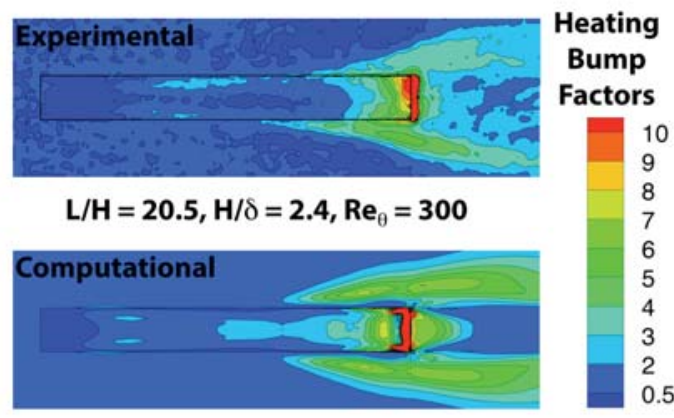

Figure 15. Comparison of predicted and measured heating augmentations at moderate Reynolds number (Fig. 10 from Ref. 27).

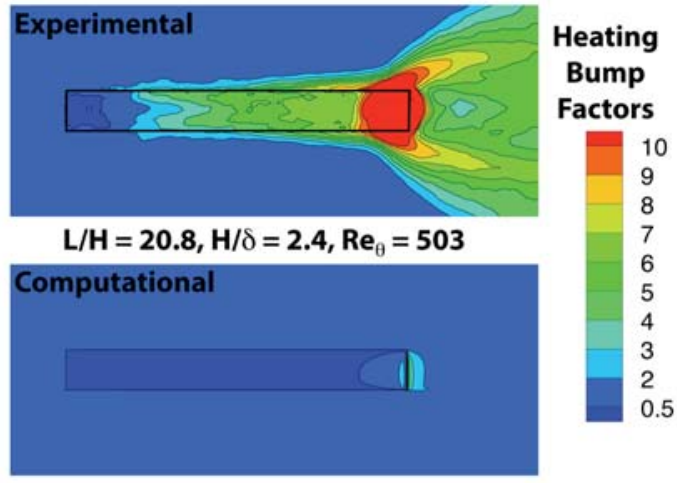

Figure 16. Comparison of predicted and measured heating augmentations at high Reynolds number (Fig. 13 from Ref. 27). 

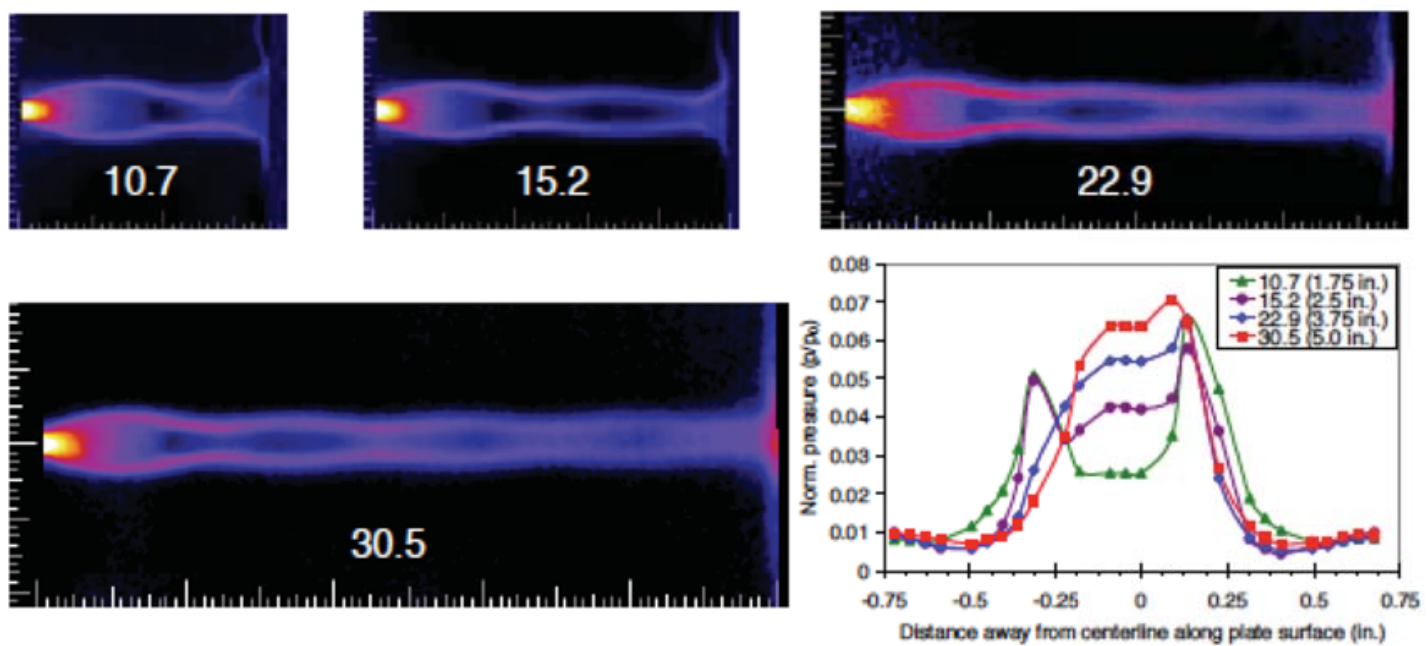

Figure 17. Effect of impingement length on jet shock structure and impingement pressure for jet pressure ration of 5.7 (Fig. 19 from Ref. 29).

Wing leading edge surface breaches were also examined in the LAL using a variety of test techniques. Rufer, et al. ${ }^{28}$ conducted a study in the 31-Inch Mach 10 Air Tunnel of flow through a small hole with subsequent impingement on an internal back wall surface. Surface impingement heat flux data was obtained with the global phosphor thermography technique and compared against thin film gages. Various sized holes were investigated. The experimental results were compared against computational predictions with good agreement to the measured jet impingement width and peak location. Inman, et al. ${ }^{29}$ details a separate effort to examine the jet flow structures using PLIF flow visualization and impingement using surface pressure gages. This study was conducted using the test section of the 15-Inch Mach 6 Air Tunnel as a vacuum chamber. Figure 17 provides an example of the unique results obtained with this effort. An interesting conclusion from this figure is that while the shape of the impingement pressure profile is dependent on jet length, the peak pressure towards the outer rim of the impingement disk is largely independent of jet length. Note that the pressure profiles are incorrectly portrayed as not symmetric due to a known faulty pressure port at the -0.135 inch location.

\section{B. Hyper-X}

1. Aerodynamic Database and Stage Separation (1996-2000)

Even prior to the release of the official request for proposals in Oct. 1996, the LAL was heavily utilized for configuration screening and preliminary database development in support of the Hyper-X experimental aerodynamics effort. Following contract award for the Hyper-X research vehicle (also referred to as X-43A) in March 1997, the experimental aerodynamic program focused on configuration optimization and maturation, followed by ADB benchmarking for all phases of the flight trajectory. ${ }^{30}$ An extensive wind tunnel test program was conducted to develop the ADB, which included tests within the LAL for the hypersonic portion of the trajectory. CFD was used to account for open cowl powered and unpowered flight characteristics. Stage separation tests were also conducted in the LAL, which allowed an early assessment of the order of magnitude of the

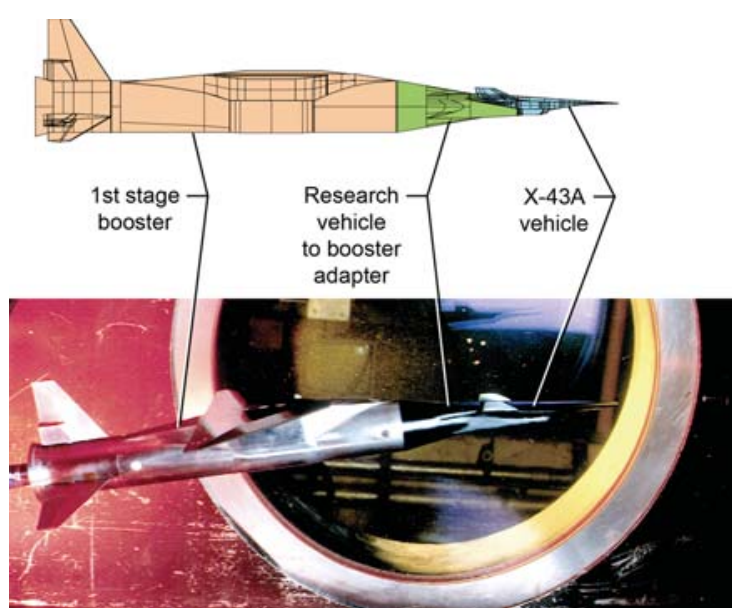

Figure 18. Hyper-X launch configuration undergoing aerodynamic testing in the NASA LaRC 20-Inch Mach 6 Air Tunnel (modified Fig. 7 from Ref. 30). 
interference effects and aided in the development of required parametrics for the interference aerodynamic database. The vehicle guidance, navigation, and control characteristics were derived from the largely experimental ADB.

Figure 18 (from Ref. 30) provides a sample photograph of the $3 \%$ scale aerodynamic model of the launch configuration installed in the 20-Inch Mach 6 Air Tunnel. This configuration consisted of the X-43A attached to the first stage booster (a modified Pegasus Rocket) via a specially designed conically shaped adapter. The experimentally derived aerodynamic database was generated on the $\mathrm{X}-43 \mathrm{~A}$ configuration with the engine inlet in the closed position, and CFD was used to adjust the airframe force and
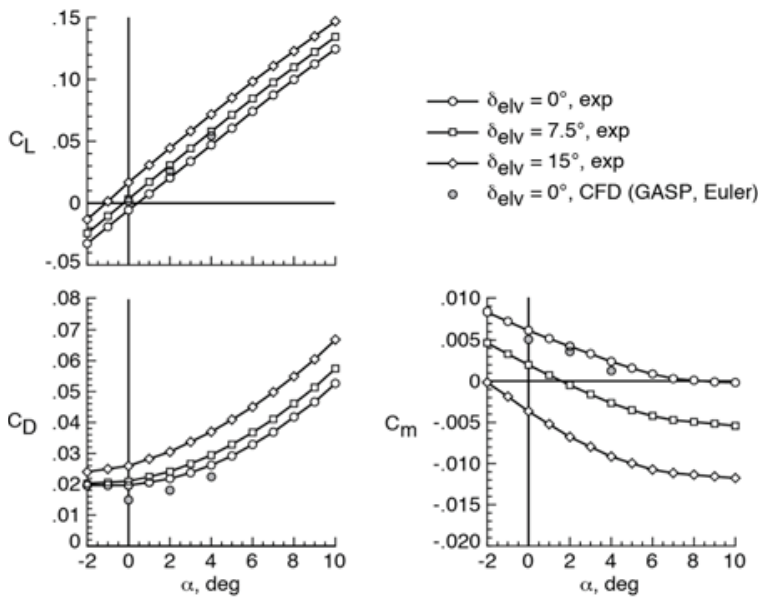

Figure 19. X-43A Mach 6 basic longitudinal aerodynamic characteristics with inlet closed, wind tunnel vs. CFD (Fig. 11 from Ref. 30).

moment increments to account for unpowered and powered inlet-open engine modes. Figure 19 (from Ref. 30) provides an example of validated computational predictions for the X-43A with the inlet closed against experimentally obtained longitudinal aerodynamic characteristics (lift, drag, and pitching moment) from the 20-Inch Mach 6 Air Tunnel. The discrepancies in the CFD drag predictions are attributed to the inviscid analysis.

Another unique experimental contributions to the Hyper-X program was the stage separation test program. ${ }^{31}$ Figure 20 (from Ref. 31) provides a photograph of one of the stage separation rigs set up in the 31-Inch Mach 10 Air Tunnel to study interference effects of the booster adapter in close proximity to X-43A. This rig allowed an early preliminary assessment of the order of magnitude of the interference aerodynamics. Figure 21 (also from Ref. 31) provides an example Schlieren photograph taken in the 20-Inch Mach 6 Air Tunnel showing the interference shocks between booster adapter and X-43A just as the separation process starts.

\section{Forebody tripping (1997-2000)}

$\mathrm{X}-43 \mathrm{~A}$ was conceived as a sub-scale test bed for a much larger NASP-like vehicle. At full scale, the longer forebody length would be sufficient to provide a naturally turbulent boundary layer for the scramjet inlet, which was deemed beneficial for engine operability. Thus, boundary layer trips were needed for X$43 \mathrm{~A}$ to provide traceability and scalability to the future full-scale vehicle. The 20-Inch Mach 6 Air and 31-Inch Mach 10 Air Tunnels were used to experimentally examine BL trips for X-43A to both compare and contrast (screen) concepts, as well as to finalize and scale the selected configuration for both the Mach 7 and 10 flight vehicles. The development effort was detailed in Ref. 32 while the analysis of the flight trip performance results was presented in Ref. 33. Flight success was enhanced by the experimental effort to screen trips and then determine the proper scaling for wind tunnel to flight. The selected trip configuration sized for the Mach 7 flight is shown in Fig. 22. The X-

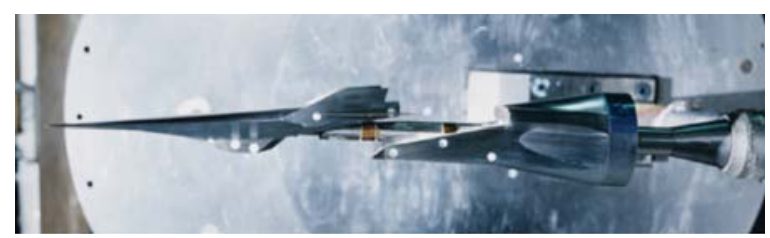

Figure 20. Photograph of $X-43 A$ stage separation interference test setup in 31-Inch Mach 10 Air Tunnel (Fig. 5 from Ref. 31).

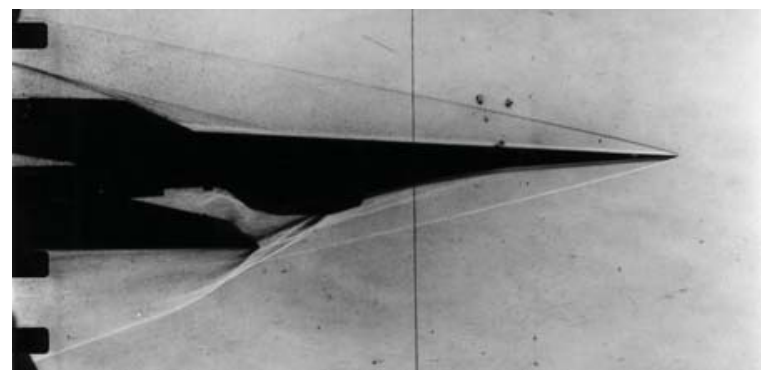

Figure 21. Schlieren photograph of X-43A stage separation test in 20-Inch Mach 6 Air Tunnel

(Fig. 11b from Ref. 31). 


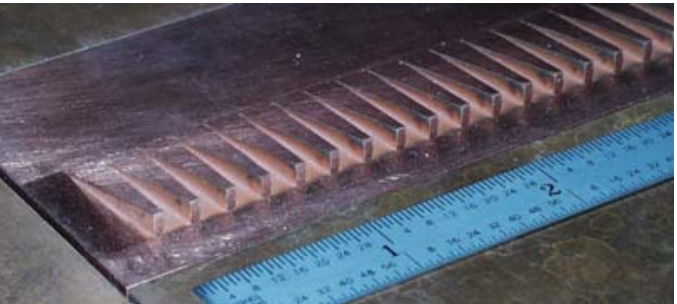

Figure 22. Final trips scaled for Mach 7 flight. (Fig. 22 from Ref. 32).

$43 \mathrm{~A}$ trips, a spanwise array of vortex generators sized to fit within the boundary layer, have become the standard for transition augmentation on slender hypersonic vehicles.

Figure 23 provides visual evidence of the impact of boundary layer trips of the first ramp of the Hyper-X forebody. Without the trips, the ramp corners promote small regions of separated flow that appear to enhance lateral spillage of the ramp boundary layer away from the inlet. The separation zone on the first ramp break also appears to amplify the separation zones along the chine. The trip array provides streamwise vorticity within the boundary layer sufficient to both reduce lateral spillage and diminish the separations.

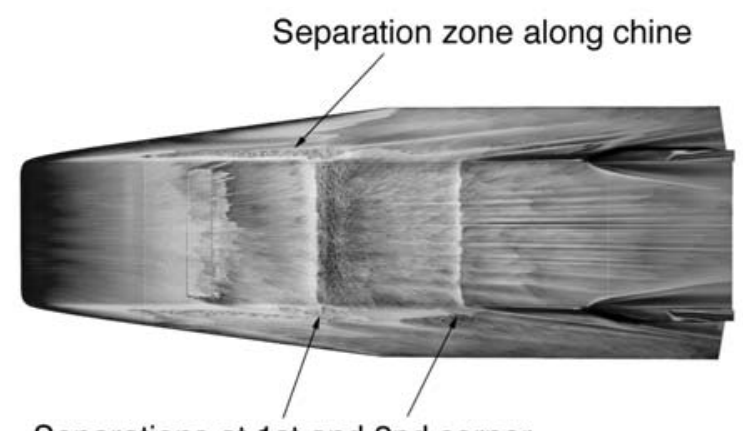

Separations at 1 st and 2 nd corner

(a) No trips.

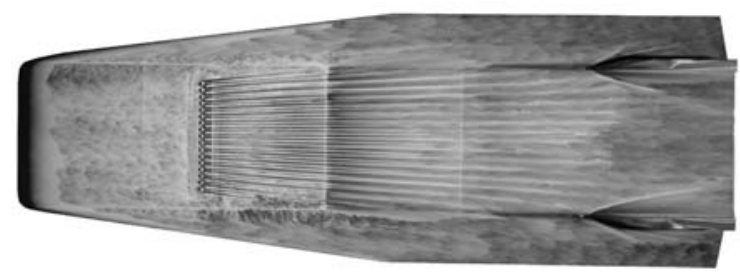

(a) Trips.

Figure 23. Comparison of Hyper-X oil flow results in the $20 \mathrm{M} 6$ with and without boundary layer trips (Fig. 7 \& 14b from Ref. 32).

\section{X-Plane Support}

\section{X-33 BLT (1995-2000)}

A significant amount of testing was done in support of the X-33 program beginning with the Phase I screening of 3 different configurations, followed by high fidelity tests of the selected Phase II configuration from the Lockheed Martin Skunk Works. Much of the Phase I activity has never been published and is still considered proprietary data. The Phase II X-33 configuration showing the notional TPS layout is provided in Fig. 24. Comparisons of the X-33 Phase II configuration experimental aerodynamic and aeroheating results to computational predictions were provided in Refs. 34 - 37. Reference 38 provided an initial assessment of boundary layer transition on the X-33 configuration and discussed the trajectory shaping function designed to reduce or optimize flight thermal environments. Based on the correlation approach described earlier, transition could be predicted on the windward surface using computed BL properties as a function of the trajectory from three basic inputs: altitude, velocity, and angle of attack. While this project did not proceed to flight, the approach outlined for using a numerical function based on BL transition to reduce aeroheating environments through trajectory tailoring could be applicable to other future programs. The basic BLT prediction methodology was shown as viable with the post-RTF Shuttle flights.

Figure 25 provides confirmation of measured attachment line locations via oil-flow in comparison to computationally predicted

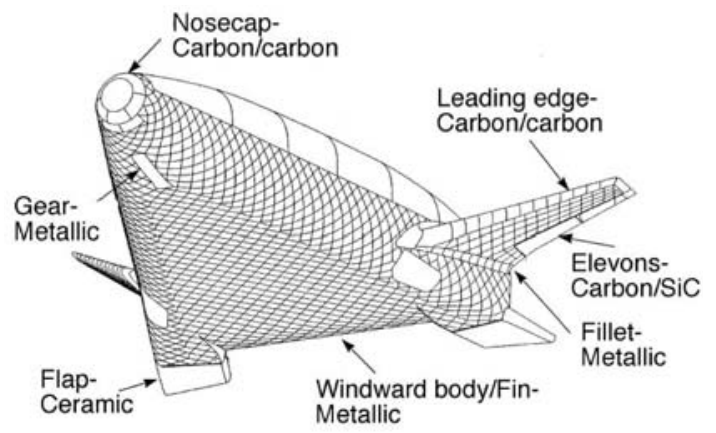

Figure 24. X-33 windward surface TPS (Fig. 2 from Ref. 39). 
fiducial marks on one-half of the windward plane. For this $\alpha=30-\mathrm{deg}$ case, the middle fiducial marks identified with a "-30" (for $\alpha=30$-deg) represent the dividing line from which the oil either flows outboard (towards the chine) or inboard (towards the trailing edge). Figure 26 provides a sample heat transfer image at $\alpha=40$ deg and $R e_{\infty}=3.1 \times 10^{6} / \mathrm{ft}$ with identical sized trips, $k=0.005$-in, placed on the centerline and attachment lines. Note that the attachment line trips appear effective while the centerline is somewhat less so, which is an indication that the boundary layer is thinner along the attachment lines.

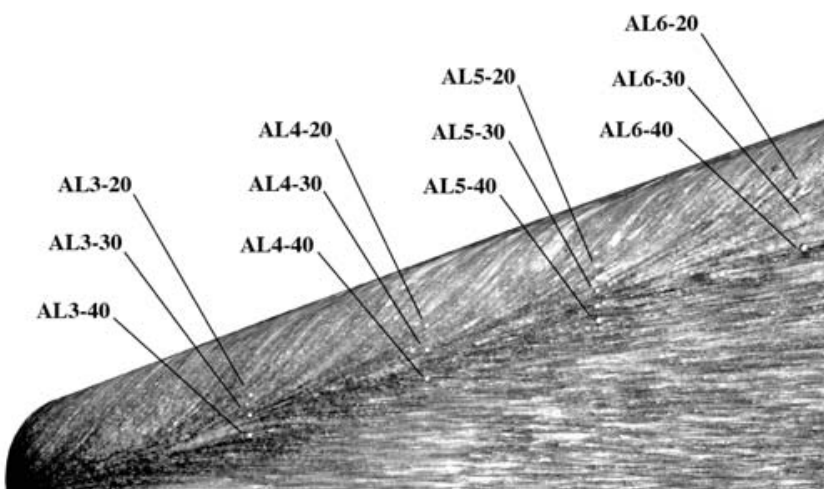

Figure 25. Sample X-33 oil flow confirming location of predicted windward attachment lines in the 20Inch Mach 6 Air Tunnel (Fig. 13 from Ref. 39).

Once the attachment line locations were verified, an extension of the discrete roughness correlations could be extended to locations beyond just the centerline, as had previously shown from the Shuttle asymmetric BL transition study. The combination of the earlier Shuttle work with the X-33 results and additional data obtained on the X-38 configuration, provided confidence that applicability with this correlation approach was viable.

One additional aspect of the X-33 BLT study worth noting is the effort to characterize the effect of surface panel bowing on BL transition. Figure 27 provides a sample global heat transfer image at $\alpha=40-\mathrm{deg}$ and $R e_{\infty}=4.0 \times 10^{6} / \mathrm{ft}$ showing the wavy wall effect (with a nominal bow height of $k=$ 0.008-in) on the transition front. It was determined that the discrete roughness correlation represented a worse case, as reflected in comparing these two examples: a smaller discrete trip is fully effective at a lower Reynolds number than these extreme bow heights at a higher Reynolds number. The bowed panels did provide more of a distributed influence on the transition front however. These examples were all taken from Ref. 39.

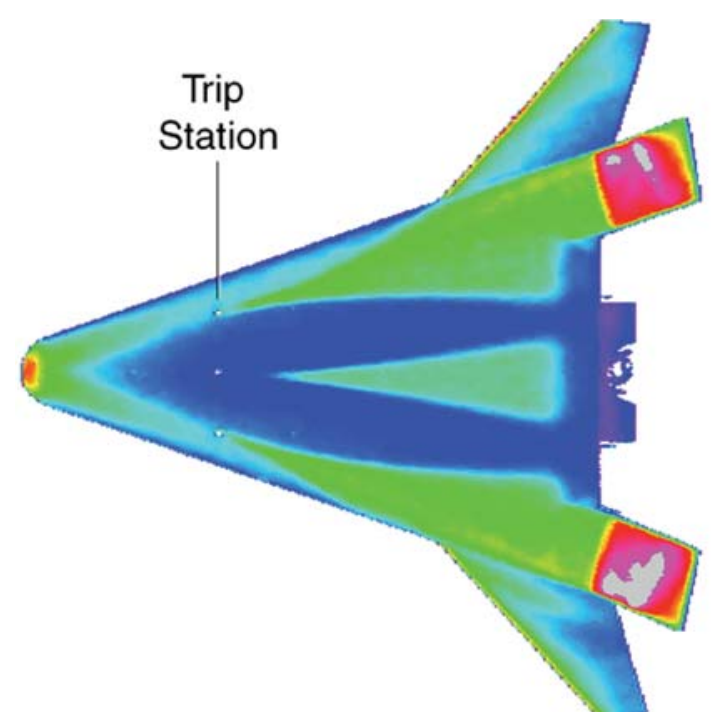

Figure 26. Sample X-33 global heating image showing effect of discrete trips on windward centerline and attachment lines in the 20-Inch Mach 6 Air Tunnel (Fig. 15a from Ref. 39).

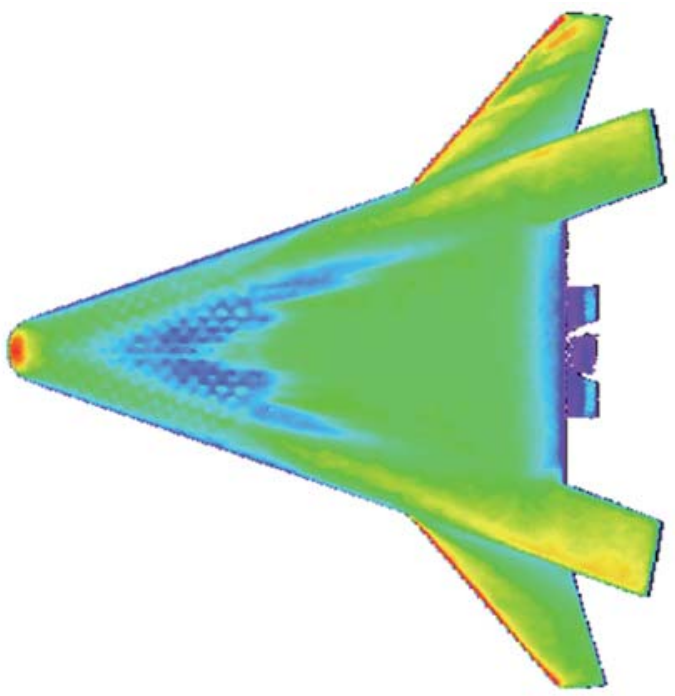

Figure 27. Sample $\mathrm{X}-33$ global heating image showing effect of wavy walls on windward forebody in the 20-Inch Mach 6 Air Tunnel (Fig. 21 from Ref. 39). 
2. X-34 Aerothermodynamics (1995-2002)

Simultaneous to the other X-plane programs discussed here, a somewhat smaller experimental effort was underway to define the aerothermodynamic environments for the X-34 program. Aerodynamic and aeroheating tests on Orbital Sciences proposed X-34 configuration (Fig. 28) were completed in the LAL. Brauckmann 40 provides details of the aerodynamic data and analysis. Pamadi, et al. ${ }^{41}$

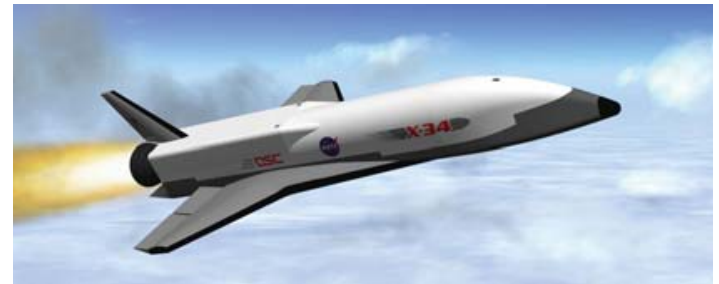

Figure 28. Artist sketch of $X-34$ ascent (Fig. 1 from Ref. 42).

discusses the ADB development work that was performed in support of guidance and control of the vehicle in flight. While the X-34 was cancelled prior to flight, this effort does highlight an approach whereby only Langley facilities were used to generate the flight aerodynamic database across the speed regime (including the LAL for hypersonics). On an aeroheating side, the LAL was also used to derive flight environments. Figures 29 and 30 provide an example whereby wind tunnel global heating rates were extrapolated to flight conditions for both laminar and turbulent boundary layers and compared to CFD predictions. The extrapolation method was discussed in Berry, et al..$^{42}$ Note, that for the turbulent extrapolation case, a boundary layer trip on centerline was used for the phosphor data such that only the results downstream of the trip should be considered in comparisons between the data and prediction.

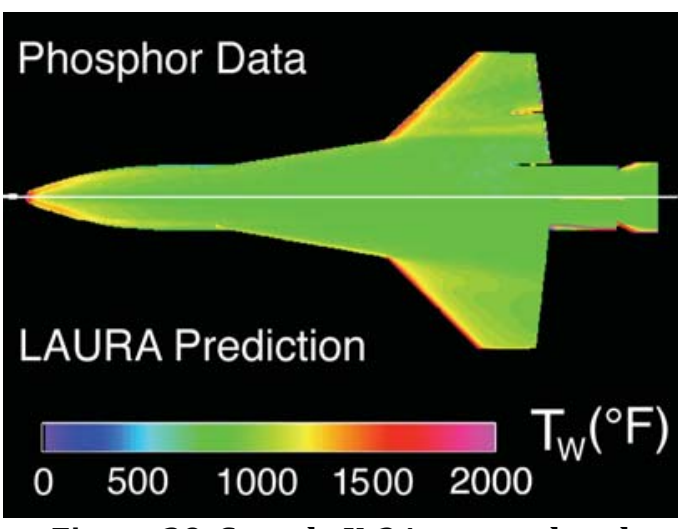

Figure 29. Sample X-34 extrapolated heating to laminar flight conditions with comparison to predictions (Fig. 20a from Ref. 42).

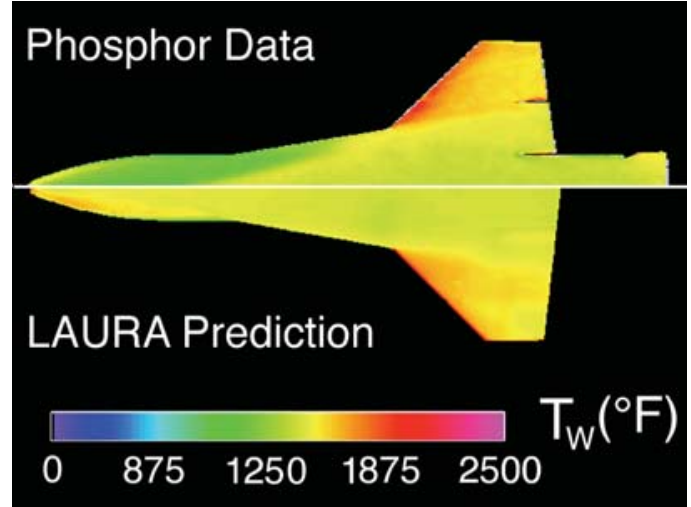

Figure 30. Sample X-34 extrapolated heating to turbulent flight conditions with comparison to predictions (Fig. 20a from Ref. 42).

\section{X-37 OML Screening (1999-2004)}

The LAL was heavily involved in the development of the aerothermodynamic environments in support of the X-37 program, although none of these data are publically available. Experimental testing conducted on the X-37 and precursor X-40 configurations include work on wing/body strake modifications, nose bluntness and wing shaping, control surface definition and effectiveness, and support for defining the heating environments for TPS design. This vehicle has successfully flown many times. Recently, this configuration was suggested as a potential pathway to a reusable human taxi to low Earth orbit. 43

\section{X-38 TPS Environments (1995-2001)}

In support of the X-38 program, the LAL was instrumental in providing early aerodynamic screening and configuration development and the BLT roughness criterion used for TPS design. Figure 31 provides an artist's sketch of the X-38 docked at the International Space Station for use as a lifeboat. Testing also included heavy gas $\left(\mathrm{CF}_{4}\right)$ studies to better

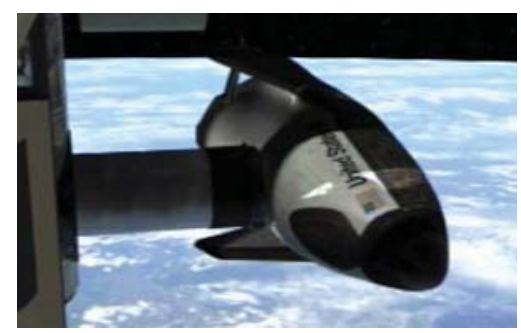

Figure 31. X-38 as a lifeboat for the International Space Station (Fig. 1 from Ref. 45). 


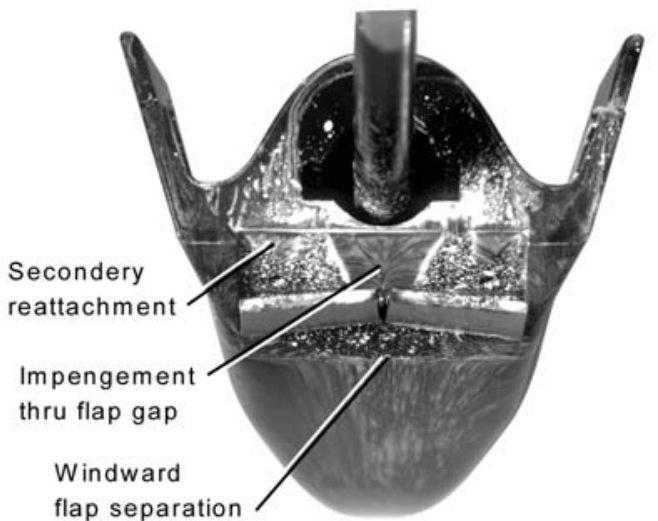

Figure 32. X-38 surface streamlines on the flap cavity floor at Mach 6 in air, $\alpha=40 \mathrm{deg}$, $\operatorname{Re}_{\mathrm{L}}=2.0 \times 10^{6}$, and $\delta_{\mathrm{BF}}=20 \mathrm{deg}$ (Fig. 28 from Ref. 44).

understand and characterize BF effectiveness, as discussed by Refs. 44 and 45 . Although this program was cancelled prior to flight, the BLT data provided confidence in the applicability of the correlation method in support of the Shuttle RTF BLT Tool. ${ }^{46}$ Unique experimental examples from this effort include work to characterize the flow through the split body flaps with impingement on the cavity floor, as shown in the oil-flows of Fig. 32 and the discrete thin film gage data of Fig. 33. Interpolation of the discrete heating data for presentation as a color contour map in Fig. 30 helps to show the cavity floor impingement heating as strongly influenced by $R e$.

\section{DoD/Air Force Support}

1. HIFiRE (2006-2012)

In 2006, the US Department of Defense (DoD) and the Air Force Research Laboratory (AFRL), entered into a joint project agreement with the Australian Department of Defense to conduct collaborative research into hypersonic technologies under the Hypersonic International Flight Research and Experimentation (HIFiRE) program. Dolvin ${ }^{47}$ provides details of the 9 proposed HIFiRE flight projects, several of which were designated to be led by the US, specifically HIFiRE 1, 5 and 9 for aerosciences and HIFiRE 2 and 6 for propulsion. To date, the LAL has been used to test three HIFiRE configurations: 1,5 and 6.

The primary payload for the HIFiRE 1 flight was a 7 deg cone-cylinder-flare configuration, approximately 6.3 feet in length at full scale. Wind tunnel testing was completed on a $20 \%$ scale model of the full vehicle and a 35\% scale model of the fore cone only (see Fig. 33). ${ }^{48}$ LAL testing for HIFiRE 1 provided BLT data for trip sizing required for a flight secondary goal. The primary goal of the flight test was to obtain natural BLT data, so a trip size and location was found such that it would only affect one quadrant of the axisymmetric configuration. The LAL testing identified a location further aft on the flight vehicle to minimize contamination of the turbulent wedge onto the three natural BLT quadrants of the vehicle. Allowable roughness height criteria were also established from the experimental data to ensure that steps near the nose did not prematurely trip the BL during flight. Figure 34 provides a sample result from Ref. 48 showing the effect of trip height on transition 

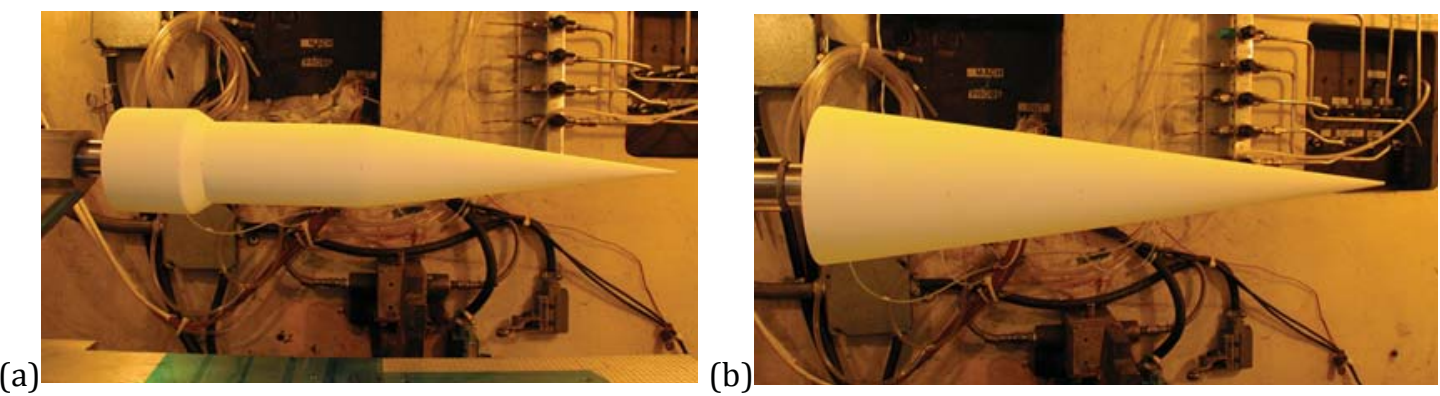

Figure 34. HIFiRE 1 models installed in the 20-Inch Mach 6: (a) 20\% scale Full Vehicle (b) $35 \%$ scale Forecone (Fig. 2 from Ref. 48).
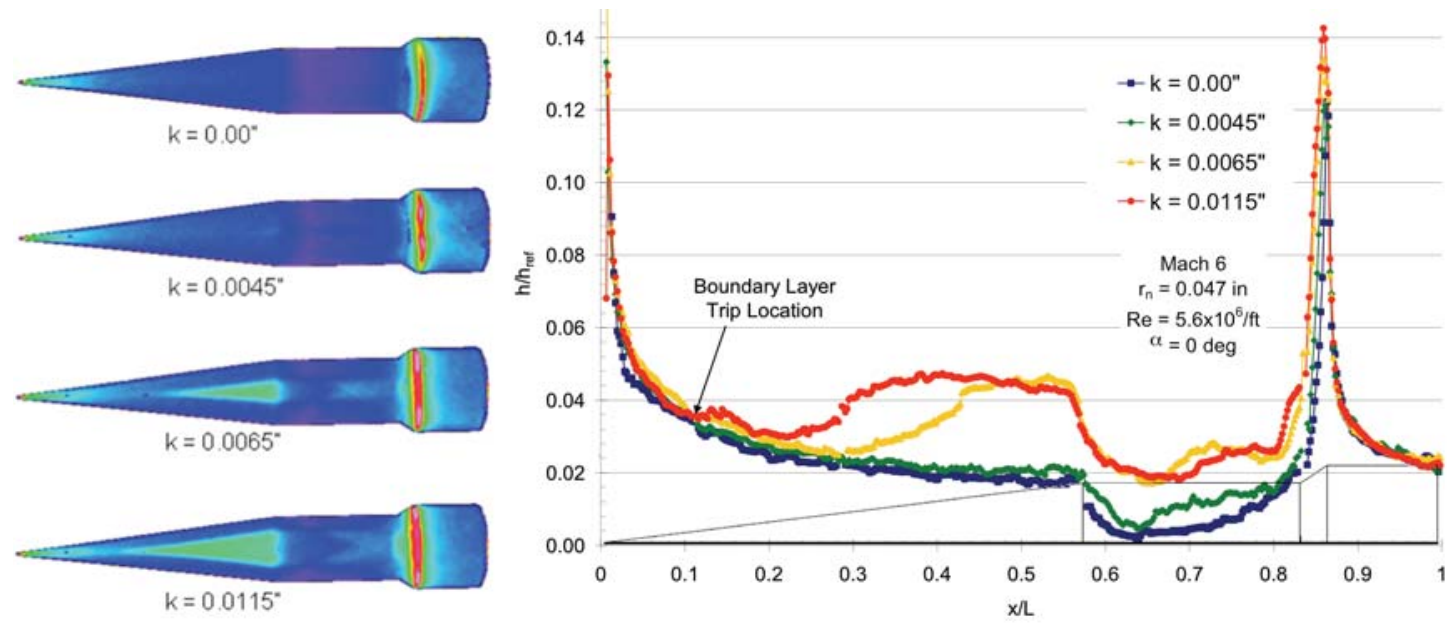

Figure 35. Comparison of BL trips on the $20 \%$ scale model (Fig. 9 from Ref. 48).

with the cone-cylinder-flare configuration. The vehicle flew successfully in March 2010. References 49-52 provide an assessment of the HIFiRE 1 flight results.

The HIFiRE-5 configuration is a 2:1 elliptic cross-section cone (see Fig. 36) designed to further investigate BLT in flight. Ground testing was used to determine the expected heating patterns and behaviors associated with the BLT onset. Windside, leeside and side effects were examined. A significant effort was put into understanding the effects of two-dimensional trips (designed to simulate the effects of a step in the joints between the nose and body sections of the vehicle) and three-dimensional trips (designed to simulate the possible protuberances associated with hardware on the vehicle). Figure 37 from Ref. 53 provides an assessment of angle of attack effects, showing the three dimensional nature of the transition front for this vehicle. The vehicle launched successfully in April 2012 but did not reach hypersonic speeds due to issues with the $2^{\text {nd }}$ stage booster. Kimmel, et al. ${ }^{54}$ provided a preliminary assessment of these flight results.

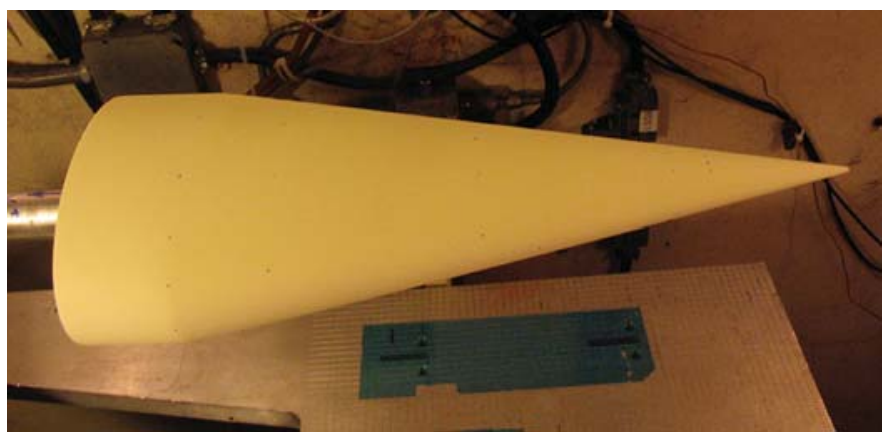

Figure 36. HIFiRE 5 model installed in the 20-Inch Mach 6 Tunnel. 

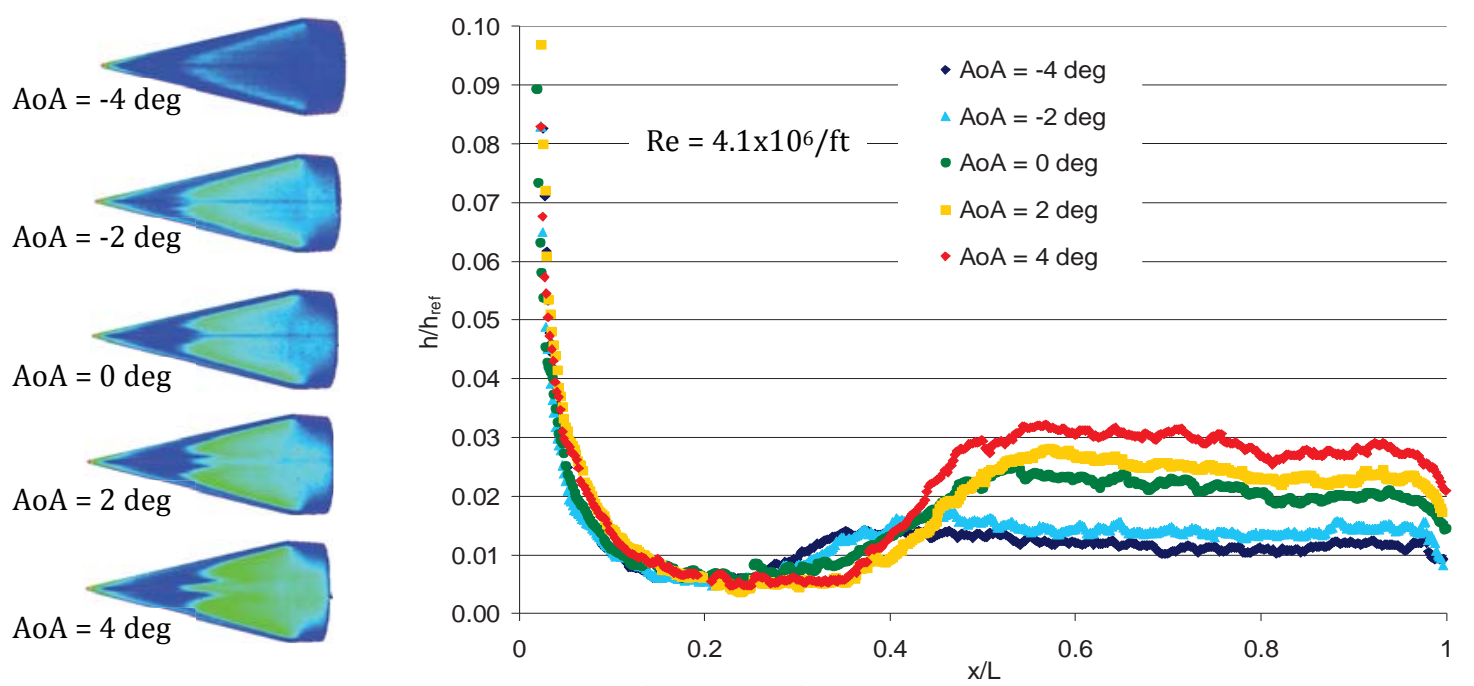

Figure 37. HIFiRE 5 angle of attack effects (Fig. 8 from Ref. 53).

HIFiRE-6 is a scramjet flight configuration with an unpowered flow through inlet in flight. The ground testing included aerodynamic F\&M measurements as well as schlieren measurements to look at the performance of the inlet on the vehicle configuration and help determine flight configuration details. The data from this testing have not yet been published. Also, this vehicle has not yet flown.

\section{2. $X-51(2007-2010)$}

A significant effort was put into understanding the heating, flow field and BLT characteristics of the X-51, a scramjet engine flight program. The 20-Inch Mach 6 Air Tunnel was used to test the BLT trip configuration (designed to be similar to the Hyper-X trips noted previously) and determine the optimum BLT trip height for flight. Oil flow testing was used to gain a better understanding of the flow field leading up the ramp and into the inlet. Leeside heating and BLT characteristics also were examined. There were 2 successful flights of X-51 in May 2010 and May 2013, while there were two other unsuccessful flights, one due to engine unstart (June 2011) and the other due to mechanical failure (August 2012). The BL trips first developed for X-43A have now been used for the X-51 flight vehicle. There are no published results, thus far, for this program.

\section{Falcon HTV (2008-2013)}

The LAL provided support for the Defense Advanced Research Projects Agency (DARPA)'s Falcon Hypersonic Technology Vehicle (HTV) 1 and 2 programs, specifically the NASA Langley 20-Inch Mach 6 and 31-Inch Mach 10 Air Tunnels. As a result of the testing, a better understanding was gained of the boundary later transition behavior and surface flow characteristics of both vehicles were obtained. Testing for the HTV-1 program focused on aeroheating aspects and was conducted using scaled ceramic phosphor thermography models. A range of angles of attack, sideslip angles, Reynolds numbers and control surface deflections were investigated. Testing for the HTV-2 program included the same parametrics as the HTV-1 program as well as aerodynamic testing in both facilities. Most of these results have not been published.

\section{E. Other Recent Programs}

1. HyBoLT (2006-2008)

A flight of opportunity became available in 2006 with the maiden launch by ATK of a developmental multi-stage rocket, the ALV X-1. The HyBoLT (Hypersonic Boundary Layer Transition) flight experiment was quickly developed with the intent of minimizing impact on the proposed ALV X-1 launch schedule, which was to be launched within a year from the NASA Wallops Flight Facility (WFF). Figure 38 provides an artistic rendering of HyBoLT and ALV X-1 launching from the WFF facility. The HyBoLT flight experiment was proposed to obtain code validation data for 
prediction of hypersonic boundary layer transition. The flight experiment was designed to allow for independent objectives on each side of the vehicle. One side was dedicated to investigating smooth wall transition (referred to as Side A) and the other side was dedicated to discrete roughness transition (Side B) in support of the Shuttle RTF effort. Figure 39 provides a sample result showing the experimental Side B turbulent wedges in reference to the flight instrumentation on a phosphor image mapped to the CAD geometry. This was done as a check to see if the instrumentation layout was adequate for

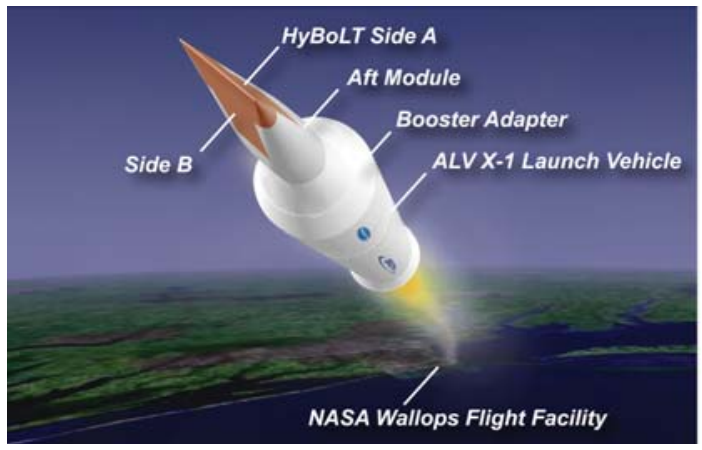

Figure 38. Artistic rendering of HyBoLT during launch from Wallops Flight Facility. mapping the transition front movement during flight. Figure 40 provides the effect of Reynolds number, showing the location of the turbulent wedges for laminar, incipient and, effective conditions. These three figures were taken from Ref. 55. In particular, the LAL testing was crucial for understanding if the instrumentation layout, which due to this program's fast pace nature had to be finalized prior to the test, was adequate for the task. The launch took place in Aug. 2008 and had to be terminated early due to a flight guidance and control issue. ATK choose not to pursue a second test of this rocket design, so there was no follow-on flight attempt.

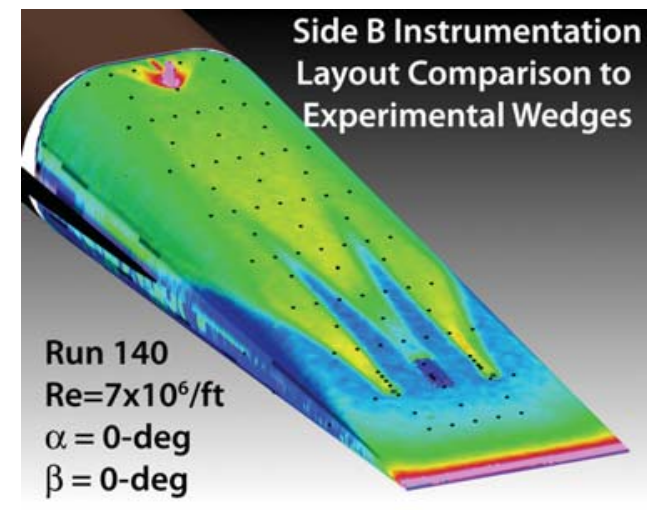

Figure 39. Wind tunnel results showing location of turbulent wedges in comparison to the HyBoLT flight vehicle instrumentation.

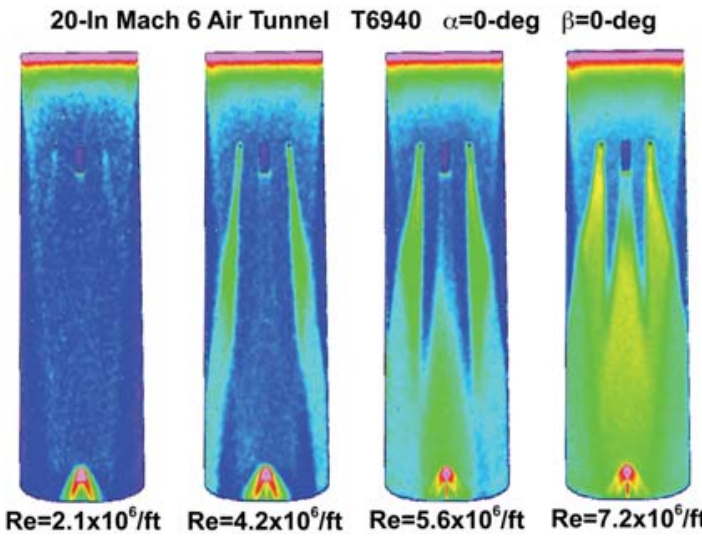

Figure 40. Wind tunnel results showing location of turbulent wedges for range of unit Reynolds numbers.

\section{Sierra Nevada Dream Chaser (2013-2014)}

The Sierra Nevada Corporation's (SNC) Dream Chaser ${ }^{\circledR}$ spacecraft (based on NASA's HL-20 design) was recently tested in the 31-Inch Mach 10 and 20-Inch Mach 6 Air Tunnels in order to reduce risk and improve the reliability of the design. The models tested were cast ceramic, approximately 10 inches long and were designed to measure heating rates associated with re-entry, including on the acreage, lower- and upper-body flaps, elevons and a rudder. The heating data were measured using phosphor thermography and will be used to help determine appropriate thermal protection system materials and will serve as a comparison to computational predictions. These recent tests provided SNC with proprietary experimental aeroheating data, so no results have been published in the open literature. However, older NASA HL-20 results are available in Ref. 56. 


\section{Summary}

A review has been provided of recent experimental aerothermodynamic contributions made by NASA Langley to many high profile national slender and/or winged-body hypersonic flight programs. Many of these examples attest to the continued need for an experimental hypersonic capability even in times of fiscal austerity. While some of the older examples, such as the body flap anomaly, are now able to be addressed through computational means, other examples, such as those related to boundary layer transition prediction, still require experimental capabilities. Several examples point to the utility of experimental means in the investigation and reconstruction of in-flight anomalies. Further, in many of these cases the wind tunnels allowed rapid assessment and screening of vehicle configurations far faster than could have been accomplished computationally. The experimental programs also provided benchmark data for verification and validation of computational results. For future hypersonic flight programs, aerothermodynamic wind tunnels will continue to be critical for reducing uncertainties due primarily to the issue of boundary layer transition during flight. The views, opinions, and/or findings contained in this article/presentation are those of the authors and should not interpreted as representing the official views or policies of the Department of Defense or the U.S. Government.

\section{References}

${ }^{1}$ Hollis, B. R., Berger, K. T., Berry, S. A., Brauckmann, G. J., Buck, G. M., DiFulvio, M., Horvath, T. J., Liechty, D. S., Merski, N. R., Murphy, K. J., Rufer, S. J., and Schoenenberger, M., "Entry, Descent, and Landing Aerothermodynamics: NASA Langley Experimental Capabilities and Contributions," AIAA

2 Heppenheimer, T. A., "Facing the Heat Barrier: A History of Hypersonics," NASA-SP-2007-4232, 2007, pg. 232.

3 Haney, J. W., "Orbiter (Pre STS-1) Aeroheating Design Data Base Development Methodology: Comparison of Wind Tunnel and Flight Test Data," NASA CP 3248, Part 2, pp. 607-675.

4 Miller, C. G., "Aerothermodynamic Flight Simulation Capabilities for Aerospace Vehicles," AIAA Paper 98-2600, June 1998.

5 Micol, J. R., "Hypersonic Aerodynamic/Aerothermodynamic Testing Capabilities at Langley Research Center: Aerothermodynamic Facilities Complex," AIAA Paper 95-2107, June 1995.

6 Micol, J. R., "Langley Aerothermodynamic Facilities Complex: Enhancements and Testing Capabilities," AIAA Paper 98-147, Jan 1998.

7 Berger, K. T., Rufer, S., Hollingsworth, K., and Wright, S., "Langley Aerothermodynamics Labs: Testing Capabilities," to be published at AIAA winter meeting, Orlando, FL, 2015.

8 Merski, N. R., "Reduction and Analysis of Phosphor Thermography Data with the IHEAT Software Package," AIAA Paper 98-0712, January 1998.

9 Buck, G. M., "Rapid Fabrication and Testing for Aerospace Vehicles," AIAA Paper 2000-0826, Jan. 2000.

10 Danehy, P.M., Wilkes, J.A., Alderfer, D.W., Jones, S.B., Robbins, A.W., Patry, D.P., and Schwartz, R.J., "Planar laser-induced fluorescence (PLIF) investigation of hypersonic flowfields in a Mach 10 wind tunnel (invited)," AIAA Paper 2006-3442, June 2006.

11 Brauckmann, G. J., Paulson, J. W., Jr., and Weilmuenster, K. J., "Experimental and Computational Analysis of Shuttle Orbiter Hypersonic Trim Anomaly," Journal of Spacecraft and Rockets, Vol. 32, No. 5, Sept-Oct 1995, pp. 758-764.

12 Muylaert, J., Walpot, L., Rostand, P., Rapuc, M., Brauckmann, G., Paulson, J., Throckmorton, D., and Weilmuenster, K., "Extrapolation from Wind Tunnel to Flight: Shuttle Orbiter Aerodynamics," AGARD AR-319, Vol.2, December 1998.

${ }_{13}$ Muylaert, J., Rostand, P., Rapuc, M., Paulson, J., Brauckmann, G., Throckmorton, D., and Steijl, R., "NASA and ESA Ground Facility Simulations of Shuttle Orbiter Aerothermodynamics," Proceedings of 
AGARD Symposium on "Future Aerospace Technology in the Service of the Alliance", Palaiseau, France, April 1997. AGARD CP-600, Vol.3, December 1997.

14 Berry, S. A., Bouslog, S. A., Brauckmann, G. J., and Caram, J. M., "Shuttle Orbiter Experimental Boundary-Layer Transition Results with Isolated Roughness," Journal of Spacecraft and Rockets, Vol. 35, No. 3, 1998, pp. 241-248.

15 Bouslog, S. A., Bertin, J. J., Berry, S. A., and Caram, J. M. "Isolated Roughness Induced BoundaryLayer Transition: Shuttle Orbiter Ground Tests and Flight Experience," AIAA Paper 97-0274, January 1997.

16 Berry, S. A., Hamilton, H. H., and Wurster, K. E., "Effect of Computational Method on Discrete Roughness Correlations for Shuttle Orbiter," Journal of Spacecraft and Rockets, Vol. 43 No. 4, 2006, pp. 842-852.

17 Horvath, T. J., "Experimental Aerothermodynamics in Support of the Columbia Accident Investigation," AIAA Paper 2004-1387, Jan 2004.

18 Brauckmann, G. J., and Scallion, W. I., "Experimental Hypersonic Aerodynamic Characteristics of the Space Shuttle Orbiter for a Range of Damage Scenarios," AIAA Paper 2004-2280, June 2004.

${ }^{19}$ Campbell, C. H., Bourland, G., Bouslog, S. A., Horvath, T. J., Berry, S. A., Gnoffo, P. A., Reuther, J., Chao, D., Anderson, B., and Picetti, D., "Orbiter Return-To-Flight Entry Aeroheating," AIAA-2006-2917, June 2006.

20 Berry, S. A., Horvath, T. J., Greene, F. A., Kinder, G. R., and Wang, K. C., "Overview of Boundary Layer Transition Research in Support of Orbiter Return To Flight," AIAA-2006-2918, June 2006.

${ }^{21}$ Horvath, T., Berry, S., Merski, N., Berger, K., Leichty, D., and Schneider, S., "Shuttle Damage/Repair from the Perspective of Hypersonic Boundary Layer Transition - Experimental Results," AIAA-20062919, June 2006.

22 McGinley, C., Berry, S. A., Kinder, G. R., Barnwell, M., Wang, K. C., and Kirk, B. S., "Review of Orbiter Flight Boundary Layer Transition Data," AIAA-2006-2921, June 2006.

23 Berry, S. A., Horvath, T. J., Cassady, A., Kirk, B. S., Wang, K.C., and Hyatt, A. J., "Boundary Layer Transition Results From STS-114," AIAA-2006-2922, June 2006.

24 Berry, S. A., King, R. A., Kegerise, M. A., Wood, W. A., McGinley, C. B., Berger, K. T., and Anderson, B. P., "Orbiter Boundary Layer Transition Prediction Tool Enhancements," AIAA-2010-0246, Jan. 2010.

25 Everhart, J. L., "Supersonic/Hypersonic Laminar Heating Correlations for Rectangular and ImpactInduced Open and Closed Cavities," AIAA Paper 2008-1283, Jan. 2008.

26 Everhart, J. L., and Greene, F. A., "Turbulent Supersonic/Hypersonic Heating Correlations for Open and Closed Cavities," AIAA Paper 2009-1400, Jan. 2009.

27 Wood, W. A., Pulsonetti, M. V., Everhart, J. L., and Bey, K. S., "Assessment of LAURA for Laminar Supersonic Shallow Cavities," AIAA Paper 2004-2639, June 2004.

28 Rufer, S. J., Nowak, R. J., Daryabeigi, K., and Picetti, D., "Experimental and Computational Study of Underexpanded jet Impingement Heat Transfer," AIAA Paper 2009-4311, June 2009.

${ }^{29}$ Inman, J. A. (Wilkes), Danehy, P. M., Nowak, R. J. and Alderfer, D. W., "Fluorescence Imaging Study of Impinging Underexpanded Jets," AIAA Paper 2008-619, Jan. 2008.

30 Engelund, W. C., Holland, S. D., Cockrell, C. E., Jr., Bittner, R. D., “Aerodynamic Database Development for the Hyper-X Airframe-Integrated Scramjet Propulsion Experiments," Journal of Spacecraft and Rockets, Vol. 38 No. 6, Nov-Dec 2001, pp. 803-810.

31 Woods, W.C., Holland, S. D., and DiFulvio, M., "Hyper-X Stage Separation Wind-Tunnel Test Program," Journal of Spacecraft and Rockets, Vol. 38 No. 6, Nov-Dec 2001, pp. 811-819. 
32 Berry, S. A., Auslender, A. H., Dilley, A. D., and Calleja, J. F., "Hypersonic Boundary-Layer Trip Development for Hyper-X," Journal of Spacecraft and Rockets, Vol. 38, No. 6, Nov-Dec 2001, pp. 853864.

33 Berry, S. A., Daryabeigi, K, Wurster, K., Bittner, R., "Boundary-Layer Transition on X-43A," Journal of Spacecraft and Rockets, Vol. 47 No. 6, Nov-Dec 2010, pp. 922-934.

${ }^{34}$ Hamilton, H., Berry, S., Horvath, T., and Weilmuenster, J., "Computational/Experimental Aeroheating Predictions for X-33 Phase II Vehicle," AIAA Paper 98-0869, January 1998.

35 Murphy, K. J., Nowak, R. J., Thompson, R. A., Hollis, B. R., and Prabhu, R., "X-33 Hypersonic Aerodynamic Characterisitics," Journal of Spacecraft and Rockets," Vol. 38, No. 5, 2001, pp. 670-683. ${ }^{36}$ Hollis, B. R., Thompson, R. A., Murphy, K. J., Nowak, R. J., Riley, C. J., Wood, W. A., Alter, S. J., and Prabhu, R., "X-33 Aerodynamic Computations and Comparisons with Wind-Tunnel Data," Journal of Spacecraft and Rockets," Vol. 38, No. 5, 2001, pp. 684-691.

${ }^{37}$ Hollis, B. R., Horvath, T. J., Berry, S. A., Hamilton, H. H., Thompson, R. A., and Alter, S. J., "X-33 Computational Aeroheating Predictions and Comparisons with Experimental Data," Journal of Spacecraft and Rockets," Vol. 38, No. 5, 2001, pp. 658-669.

38 Thompson, R. A., Hamilton, H. H., Berry, S. A., and Horvath, T. J., "Hypersonic Boundary Layer Transition for X-33 Phase II Vehicle," AIAA Paper 98-0867, January 1998.

39 Berry, S. A., Horvath, T. J., Hollis, B. R., Thompson, R. A., and Hamilton, H. H., "X-33 Hypersonic Boundary Layer Transition," Journal of Spacecraft and Rockets," Vol. 38, No. 5, 2001, pp. 646-657.

40 Brauckmann, G. J., "X-34 Vehicle Aerodynamic Characteristics," Journal of Spacecraft and Rockets, Vol. 36 No. 2, Mar-Apr 1999, pp. 229-239.

41 Pamadi, B.N., Brauckmann, G. J., Ruth, M. J., and Fuhrmann, H. D., "Aerodynamic Characteristics, Database Development, and Flight Simulation of the X-34 Vehicle," Journal of Spacecraft and Rockets, Vol. 38 No. 3, May-Jun 2001, pp. 334-344.

42 Berry, S. A., Horvath, T. J., DiFulvio, M., Glass, C., and Merski, N. R., "X-34 Experimental Aeroheating at Mach 6 and 10," Journal of Spacecraft and Rockets, Vol. 36, No. 2, 1999, pp. 171-178.

43 Grantz, A. C., "X-37B Orbital Test Vehicle and Derivatives," AIAA Paper 2011-7315, Sept. 2011.

44 Horvath, T. J., Berry, S. A., Merski, N. R., and Fitzgerald, S. M., "X-38 Experimental Aerothermodynamics," Journal of Spacecraft and Rockets, Vol. 41, No. 2, 2004, pp. 272-292.

45 Berry, S. A., Horvath, T. J., Weilmuenster, K. J., Alter, S. J., and Merski, N. R., "X-38 Experimental Aeroheating at Mach 10," Journal of Spacecraft and Rockets, Vol. 41, No. 2, 2004, pp. 293-301.

46 Berry, S. A., and Horvath, T. J., "Discrete-Roughness Transition for Hypersonic Flight Vehicles," Journal of Spacecraft and Rockets, Vol. 45 No. 2, 2008, pp. 216-227.

47 Dolvin, D. J., "Hypersonic International Flight Research and Experimentation (HIFiRE)," AIAA Paper 2008-2581, Apr 2008.

48 Berger, K. T., Greene, F. A., Kimmel, R. L., Alba, C., and Johnson, H., "Aerothermodynamic Testing and Boundary Layer Trip Sizing of the HIFiRE Flight 1 Vehicle," Journal of Spacecraft and Rockets, Vol. 45, No. 6, 2008, pp. 1117-1124.

${ }^{49}$ Adamczak, D., Kimmel, R. L., DSTO ADV Brisbane Team, "HIFiRE-1 Flight Trajectory Estimation and Initial Experimental Results," AIAA Paper 2011-2358, June 2011.

50 Kimmel, R. L., Adamczak, D., DSTO ADV Brisbane Team, "HIFiRE-1 Preliminary Aerothermodynamic Measurements," AIAA Paper 2011-3413, June 2011.

51 Kimmel, R. L., Adamczak, D., "HIFiRE-1 Background and Lessons Learned," AIAA Paper 2012-1088, January 2012.

52 Stanfield, S. A., Kimmel, R. L., Adamczak, D., "HIFiRE-1 Data Analysis: Boundary Layer Transition Experiment During Reentry," AIAA Paper 2012-1087, January 2012. 
53 Berger, K. T., Rufer, S. J., Kimmel, R. L., and Adamczak, D., "Aerothermodynamic Characteristics of Boundary Layer Transition and Trip Effectiveness of the HIFiRE Flight 5 Vehicle," AIAA Paper 20094055, June 2009.

54 Kimmel, R. L., Adamczak, D., Juliano, T. J., DSTO ADV Brisbane Team, “HIFiRE-5 Flight Test Preliminary Results," AIAA Paper 2013-0377, January 2013.

55 Berry, S., Horvath, T., Schwartz, R., Ross, M., Anderson, B., and Campbell, C., "Infrared Imaging of Boundary Layer Transition Flight Experiments," AIAA-2008-4026, June, 2008.

${ }^{56}$ Horvath, T. J., Rhode, M. N., and Buck, G. M., "Aeerothermodynamic Measurements on a Proposed Assured Crew Return Vehicle (ACRV) Lifting Body Configuration at Mach 6 and 10 in Air," AIAA paper 1990-1744, June 1990. 